\title{
Institutional Quality and International Trade
}

\author{
Andrei A. Levchenko* \\ International Monetary Fund \\ First Version: October, 2003 \\ This Version: September, 2006
}

\begin{abstract}
Institutions - quality of contract enforcement, property rights, shareholder protection, and the like - have received a great deal of attention in recent years. Yet trade theory has not considered the implications of institutional differences, beyond treating them simply as different technologies or taxes. The purpose of this paper is twofold. First, we propose a simple model of international trade in which institutional differences are modeled within the framework of incomplete contracts. We show that doing so reverses many of the conclusions obtained by equating institutions with productivity. Institutional differences as a source of comparative advantage imply, among other things, that the less developed country may not gain from trade, and factor prices may actually diverge as a result of trade. Second, we test empirically whether institutions act as a source of trade, using data on US imports disaggregated by country and industry. The empirical results provide evidence of "institutional content of trade:" institutional differences are an important determinant of trade flows.
\end{abstract}

JEL Classification Codes: F11, F15, F16.

Keywords: institutional differences, incomplete contracts, comparative advantage

\footnotetext{
*I am grateful to Daron Acemoglu, Olivier Blanchard, Simon Johnson, and Jaume Ventura for invaluable guidance and support, and to Michael Alexeev, Pol Antras, Abhijit Banerjee, Bjoern Bruegemann, Ricardo Caballero, Shawn Cole, Quy-Toan Do, Rema Hanna, Aart Kraay, Paolo Mauro, John Romalis, Andrei Shleifer, Petia Topalova, Jeromin Zettelmeyer, anonymous referees, as well as seminar participants at various institutions for helpful suggestions. I am indebted to Kevin Cowan for sharing the Stata code that generates the institutional intensity measures, and to Claudio Raddatz for the data used to generate measures of external dependence. Financial support from the National Science Foundation is gratefully acknowledged. All remaining errors are my own. The views expressed in this paper are those of the author and should not be attributed to the International Monetary Fund, its Executive Board, or its management. Correspondence: International Monetary Fund, 700 19th St. NW, Washington, DC 20431. E-mail: alevchenko@imf.org.
} 


\section{Introduction}

The notion of institutions has received a great deal of attention in recent literature. The term typically refers to a wide range of structures that affect economic outcomes: contract enforcement, property rights, investor protection, the political system, and the like. Empirical evidence, in particular the series of papers by La Porta, Lopez-de-Silanes, Shleifer and Vishny (e.g. 1997, 1998), and Acemoglu, Johnson and Robinson (e.g. 2001, 2002), suggests two important facts. First, institutions matter a great deal for economic performance. Second, developed countries ("the North") have much better institutions than developing ones ("the South").

Given the emerging consensus on the primary importance of institutions, it is natural to think that institutional differences could be a source of comparative advantage in NorthSouth trade. What are the features of this trade? The starting point of the analysis is the assumption that some sectors rely on institutions more than others. Dependence on institutions - enforcement of contracts and property rights - is a technological feature of the production process in some industries. This would be the case, for example, if production could not rely on spot markets for inputs, and instead required establishing complex relationships between the factors.

Better institutions in the North then immediately suggest a pattern of "institutional comparative advantage." To model it, this paper brings to bear the insights from the incomplete contracts literature exemplified by Williamson (1985) and Grossman and Hart (1986). Contract enforcement, property rights, investor protection, and the like, matter because they allow agents to overcome frictions that arise when two parties with competing interests enter into a production relationship. We adopt a commonly used source of frictions for which quality of contract enforcement and property rights is likely to be especially important. Namely, we assume that in some sectors parties must make relationship-specific investments, leading to the well-known holdup problem. We then parameterize institutional quality in the way suggested by Caballero and Hammour (1998). This framework lends itself naturally to modeling institutional comparative advantage: in countries with worse institutions contracts are more incomplete. ${ }^{1}$

When we model institutional comparative advantage using the incomplete contracts framework, we reach some striking conclusions. While the North is certain to gain from

\footnotetext{
${ }^{1}$ Any attempt to model institutional differences in an analytical framework requires restricting attention to a particular type of institutions. Here, we focus on what Acemoglu and Johnson (2005) classify as "contracting institutions:" the arrangements that govern relationships between private economic parties, rather than those between private parties and the government.
} 
the institutional comparative advantage driven trade, the South may lose. Factor rewards may diverge as a result of trade opening. In the North, labor stands to gain the most from trade. In the South, capital gains, while labor is likely to suffer losses. Equally intriguing are the results regarding how institutional quality affects gains from trade. In particular, improving institutions in the North increases the South's gains from trade, but may lower the gains to the North itself.

What is the intuition for these results? Institutions play two key roles in our model. First, contracting imperfections lead to factor market distortions. In particular, imperfect institutions mean that even under perfect intersectoral mobility, factor rewards differ across industries. One of the factors - labor in our model - is compensated more in the institutionally dependent sector. These are the "good jobs," in which workers earn rents. Second, institutional differences are a source of comparative advantage: because Northern institutions are better, only the North will produce the institutionally dependent good under trade. After trade opening, the good jobs disappear in the South, and wages decrease as a result. By contrast, the high-paying sector in the North expands to accommodate the entire world demand, resulting in gains from trade over and above those implied by conventional factor-abundance differences. The bottom line is that North's superior institutions allow it to specialize in the more desirable industries. ${ }^{2}$

To arrive at the main results, this paper thus combines insights from two literatures. The first insight is that when contracts are incomplete, the economy exhibits inefficiencies. In particular, we know from Caballero and Hammour (1998) that factor markets are segmented: some factors' rewards differ across sectors. The second is an older literature on gains from trade in the presence of distortions, exemplified by Haberler (1950), Hagen (1958), and Bhagwati and Ramaswami (1963). These papers point out that when factor rewards are not the same across sectors, gains and losses from trade will come from a resulting expansion or contraction in the sectors with higher factor rewards. This paper's contribution is to derive just such a setting when contract incompleteness leads to segmented factor markets, and comparative advantage comes from institutional differences. ${ }^{3}$

After presenting the main results, we further illustrate the consequences of the incom-

\footnotetext{
${ }^{2}$ The underlying mechanism, which is that a reallocation of industries between countries resulting from trade will affect welfare through reallocation of rents, is more general. It could also be modeled within the efficiency wage dual labor markets framework of Bulow and Summers (1986), or in a two-sector matching model of Acemoglu (2001). In the context of the interaction between globalization and European labor market institutions, a similar argument has been made by Allais (1994).

${ }^{3}$ Also related is the work on the distribution of monopoly rents across countries under trade. For instance, Brander and Spencer (1981) show that trade policy can be used for "rent-shifting:" promoting a domestic monopoly enables a country to capture a share of global monopoly rents.
} 
plete contracts approach by contrasting it with an alternative way of formalizing institutional comparative advantage. We refer to this alternative as the Ricardian view: better institutions in the North simply mean that the North is relatively more productive in the institutionally dependent sectors. The implications are straightforward. First, all countries gain from trade. Second, the South stands to gain the most, because it stops producing the institutionally dependent goods, and thus no longer suffers the cost of its weak institutions. The latter conclusion is the opposite of those obtained under the incomplete contracts approach. What should we take away from this comparison? Poor quality of institutions may indeed manifest itself in lower measured productivity in the institutionally intensive sectors, for a variety of reasons. ${ }^{4}$ However, there is evidence that lack of proper contract enforcement also leads to significant distortions. ${ }^{5}$ Thus, modeling institutional comparative advantage in the basic Ricardian framework ignores important insights from the incomplete contract literature and may miss important parts of the story.

The central implication of the model is that institutional differences across countries are an important determinant of trade patterns. We test this prediction with data on US imports disaggregated by 4-digit SIC industry and country, and using a factor content of trade methodology developed by Romalis (2004). Romalis tests whether countries that are abundant in a factor of production capture larger US import shares in industries relatively intensive in that factor. This paper takes the factor content specification and augments it with variation in industry institutional dependence and country institutional quality to test whether countries with better institutions capture higher US import shares in more institutionally dependent sectors. The main finding is that institutional differences are in fact a significant determinant of trade flows.

This paper is part of the rapidly growing theoretical and empirical literature on the interaction of trade and institutions. The incomplete contracts framework was first applied in international trade by Grossman and Helpman (2002a, 2002b, 2005) and Antras (2003, 2005) to study international organization of production and boundaries of multinational firms. These papers typically model the differences between North and South not in terms of institutions, but in terms of technology or factor endowments. As such, they do not address the consequences of institutional differences acting as a source of comparative advantage. Subsequent papers by Costinot (2005) and Acemoglu, Antras, and Helpman (2005)

\footnotetext{
${ }^{4}$ For example, institutions may influence firms' choices of production process, e.g. Cowan and Neut (2002).

${ }^{5}$ Indeed, there is both macro-level (e.g. Blanchard and Kremer, 1997, Claessens and Laeven, 2003), and micro-level evidence (e.g. McMillan and Woodruff, 1999, Johnson, McMillan, and Woodruff, 2002a, 2002b) that institutional arrangements do influence agents' behavior in important ways.
} 
provide further theoretical treatments of how institutional differences generate comparative advantage in an environment with imperfectly enforced contracts. In an alternative approach, Vogel (2006) considers another source of friction - moral hazard - to model trade and factor accumulation in the presence of institutional differences. Also related is the work on financial comparative advantage (e.g. Matsuyama, 2005, Ju and Wei, 2005), which models how differences in the quality of the financial system - due in part to institutional differences - affect trade patterns.

The last part of this paper contributes to a recent strand of empirical literature on the role of institutions in international trade. Anderson and Marcouiller (2002) use the gravity model to demonstrate that bilateral trade is significantly affected by the trading countries' institutional quality, with better institutions leading to larger trade volumes. Ranjan and Lee (2003) show that bilateral trade volumes are more affected by institutional quality in sectors which they classify as more institutionally intensive. Schuler (2003) examines changes in the composition of trade in the countries of the former Soviet bloc, and shows that as the command economy institutions broke down, net exports in institutionally intensive sectors fell more than net exports in sectors that rely less on institutions. In a paper that followed this one, Nunn (2005) tests for institutional comparative advantage using a new measure of industry-level institutional intensity, and reaches similar conclusions. Since this paper examines industry-level trade shares rather than trade volumes, its approach is complementary to the former two papers, and much closer in spirit to the latter two.

The rest of the paper is organized as follows. Section 2 presents a model of trade in the presence of institutional differences. We first discuss the incomplete contracts approach to modeling institutional comparative advantage, and describe autarky and trade equilibria. We then explore in detail the welfare consequences of institutional comparative advantage driven trade. Section 3 describes in detail the empirical strategy and results. Section 4 concludes. Proofs of Propositions are collected in the Appendix.

\section{The Basic Model}

\subsection{The Environment}

It is useful to start with the standard Heckscher-Ohlin paradigm of trade. Consider an economy with two factors, $K$ and $L$, and three goods. Two of the goods are produced using only one factor, and thus we call them the $K$-good and the $L$-good. The mixed good, $M$, is produced with both factors. Agents have identical Cobb-Douglas utility functions in the 
consumption of the three goods,

$$
U\left(C_{K}, C_{L}, C_{M}\right)=C_{K}^{\alpha} C_{L}^{\beta} C_{M}^{\gamma},
$$

where $\alpha, \beta$, and $\gamma$ are positive and $\alpha+\beta+\gamma=1$. Given the goods prices $p_{K}, p_{L}$, and $p_{M}$, we let the numeraire be the ideal price index associated with Cobb-Douglas utility:

$$
P \equiv\left(\frac{p_{K}}{\alpha}\right)^{\alpha}\left(\frac{p_{L}}{\beta}\right)^{\beta}\left(\frac{p_{M}}{\gamma}\right)^{\gamma}=1
$$

Consumer utility maximization then leads to the following first-order conditions:

$$
\begin{aligned}
& p_{K}=\alpha \frac{C_{K}^{\alpha} C_{L}^{\beta} C_{M}^{\gamma}}{C_{K}} \\
& p_{L}=\beta \frac{C_{K}^{\alpha} C_{L}^{\beta} C_{M}^{\gamma}}{C_{L}} \\
& p_{M}=\gamma \frac{C_{K}^{\alpha} C_{L}^{\beta} C_{M}^{\gamma}}{C_{M}} .
\end{aligned}
$$

Production technology of the $K$-good and the $L$-good is linear in $K$ and $L$. Suppose that one unit of capital produces $a$ units of the $K$-good, and one unit of labor produces $b$ units of the $L$-good. Then profit maximization in the two industries implies that

$$
p_{K} a=r
$$

and

$$
p_{L} b=w,
$$

where $r$ and $w$ are the returns to capital and labor respectively.

The $M$-good is produced with a Leontief technology which combines one unit of $L$ and $x$ units of $K$ to produce $y$ units of the $M$-good. This paper takes the view that institutions matter because they facilitate transactions between distinct self-interested economic parties. The $M$-good is the only one which requires joining of two distinct factors of production, and thus it is natural to think of the $M$-good as being institutionally dependent. We now describe in detail how we use the incomplete contracts framework to model imperfect institutions, and how our approach delivers a novel source of comparative advantage: institutional differences. 


\subsection{Modeling Institutional Differences}

To model a setting in which the quality of contract enforcement and property rights matter, we adopt the approach developed by Williamson (1985), Grossman and Hart (1986), and Hart and Moore (1990). The strategy is to posit a friction that can be alleviated by appropriately designed contracts and property rights. Following Klein, Crawford and Alchian (1978) and Williamson (1985), we assume that when two distinct parties invest in joint production, some fraction of their investment becomes specific to the production relationship. Investment irreversibility makes the parties more reluctant to enter, introducing inefficiency - the well-known holdup problem. This argument has been used to analyze many kinds of relationships: between producers within a supply chain, between managers and outside investors, between firms and workers, and others.

One way to reduce the inefficiency is to write binding long-term contracts. Another is to assign property rights in a way that distributes the residual rights of control to moderate the holdup problem - this is the key idea of Grossman-Hart-Moore. Institutions - quality of contract enforcement, security of property rights, and the like - will matter a great deal for both of these solutions.

Consider the first way of resolving the holdup problem: binding contracts. Starting with Coase (1937), the transactions costs literature has argued that contracts are incomplete because it is prohibitive to set up contracts specifying all parties' payoffs in every possible state of the world. An integral part of this reasoning is that enforcement is costly. The quality of contract enforcement will therefore matter for how well contracts can succeed in resolving the holdup problem. A poorer institutional quality implies that fewer contracts can be written and enforced, and therefore the distortions created by relationship specificity will be greater.

Consider next the Grossman-Hart-Moore argument that when contracts alone cannot resolve the holdup problem, the production relationship will adjust to assign the residual rights of control to the party making specific investments. Here, the solution relies on existence of secure and transferable property rights. Just like the transactions costs literature, the Grossman-Hart-Moore literature came about to analyze firms in developed countries. Nonetheless, it typically concludes that assigning property rights optimally does not always fully eliminate the inefficiency. In countries with bad institutions, the absence of secure property rights implies that the holdup problem will be that much more severe. ${ }^{6}$

\footnotetext{
${ }^{6}$ Another effect could be that financial constraints - which again could arise in part as a consequence of bad institutions - prevent the optimal allocation of ownership (for more on this, see Macchiavello, 2005).
} 
To summarize, institutional quality determines the extent of transactional impediments that generally arise when two or more distinct parties form a production relationship. Our modeling approach follows Caballero and Hammour (1998). In this paper, we focus on the archetypal case in which the parties to the production are $K$ and $L$. Relationship-specific investments occur in production of the $M$-good. In particular, we assume that a fraction $\phi$ of capital's investment in the $M$-good sector becomes specific to the relationship. ${ }^{7}$ The parameter $\phi$ is meant to capture quality of contract enforcement and property rights, and its value will differ across countries. As the discussion above makes clear, $\phi$ is a consequence of both technological features of the production process and the institutional environment. This paper naturally emphasizes the latter interpretation. Countries are assumed to have the same underlying production technology that requires $K$ to make specific investments. What induces differences in $\phi$ across countries is the degree to which $K$ can avoid specificity by writing enforceable contracts, a reflection of a country's institutional quality.

Better institutions thus correspond to lower values of $\phi$. In other words, if contracts and property rights are well-enforced, each agent will be able to recoup its ex ante investment to a greater degree. This way of formalizing institutional differences is appealing because it leads to a concrete interpretation of what constitutes institutional quality: contracts are less incomplete in countries with better institutions. In the limiting case when $\phi=0$, institutions are perfect and we are back to the standard frictionless setting.

What are the consequences of imperfect institutions? Recall that one unit of $L$ and $x$ units of $K$ are required to produce $y$ units of $M$. After the production unit is formed, $K$ can only recover a fraction $(1-\phi)$ of the investment. In order to induce $K$ to form the production unit, it must be compensated with a share of the surplus, which is given by the revenue minus the ex post opportunity costs of the factors:

$$
s=p_{M} y-w-r(1-\phi) x
$$

We adopt the assumption that ex post the parties reach a Nash bargaining solution and each receive one half of the surplus. Thus, $K$ will only enter the $M$-good production if its individual rationality constraint

$$
r(1-\phi) x+\frac{1}{2} s \geq r x
$$

\footnotetext{
${ }^{7}$ Generally, specificity is relevant for $L$ as well. That is, fractions $\phi^{L}$ of $L$ and $\phi^{K}$ of $K$ become specific to the production unit. All that matters for the results, however, is the "net effective specificity" which in our case would be $\phi^{K} r x-\phi^{L} w$ (see more on this in Caballero and Hammour, 1998). All the results in this paper hold except for the knife-edge case in which the parameter values are such that the net effective specificity is zero. Thus, we sacrificed $\phi^{L}$ for expositional simplicity, and set $\phi^{K}=\phi$.
} 
is satisfied. This can be rearranged to yield:

$$
p_{M} y \geq w+(1+\phi) r x \text {. }
$$

\subsection{Autarky Equilibrium}

This approach to modeling institutions is easily embedded in the general equilibrium model of this section, where prices and resource allocations are endogenously determined. Notice that in general equilibrium, condition (7) can be interpreted as a joint restriction on $w, r$, and $p_{M}$, and will hold with equality.

The only remaining ingredient of the closed-economy equilibrium is market clearing. It is useful to define the following notation. Let $E$ be the share of labor force employed in the $M$-sector. This is convenient because the value of $E$ completely characterizes the resource allocation in the economy. Given $E$ and the relevant endowments $K$ and $L$, productions of the $M-, L-$, and $K$-goods are $y E L, b(1-E) L$, and $a\left(\frac{K}{L}-x E\right) L$, respectively. Goods market clearing then requires:

$$
\begin{gathered}
C_{K}=a\left(\frac{K}{L}-x E\right) L \\
C_{L}=b(1-E) L \\
C_{M}=y E L .
\end{gathered}
$$

The equilibrium in an economy endowed with $K$ units of capital and $L$ units of labor is a set of prices and the resource allocation $\left\{p_{K}, p_{L}, p_{M}, r, w, E\right\}$ characterized by equations (2) through (10).

Institutional imperfections modeled here have two key consequences. First, in general equilibrium one of the factors $-L$ in our case - is segmented: its rewards differ across sectors. Equation (7) makes it possible to calculate the reward to a unit of labor employed in the $M$-sector:

$$
w+\frac{1}{2}\left[p_{M} y-w-(1-\phi) r x\right]=w+\phi r x .
$$

It is clear from this expression that each unit of $L$ employed in the $M$-sector earns rents of size $\phi r x$.

Second, contracting imperfections imply that the outcome is inefficient. There is underinvestment in the $M$-good production, and $w$ and $r$ are lower than in the efficient case. This is intuitive. Imperfect institutions imply that it is harder to induce capital to enter the $M$-sector. Compared to the frictionless case, $w$ and $r$ must be pushed down, and $p_{M}$ pushed up to satisfy the individual rationality condition for capital (7). This is achieved 
by reducing the size of the $M$-sector, which simultaneously pushes the factors into the $K$ and the $L$-sectors, lowering $w$ and $r$ and raising $p_{M}$. The effect is monotonic in $\phi$ : higher values of $\phi$ lead to lower $E, w$, and $r$. Notice also that for a given level of $\phi$, increasing the size of the $M$-sector will raise both $w$ and $r$, thereby raising welfare of all factors employed in all sectors.

\subsection{Trade Equilibrium and Institutional Comparative Advantage}

The model is easily adapted to an international trade setting in the presence of both factor endowment and institutional differences. Suppose that there are two countries, North $(N)$ and South $(S)$, which can trade costlessly with each other. Following the standard notation, let $\bar{V}=(\bar{K}, \bar{L})$ be the vector of the world factor endowments, and let $\left(V^{N}, V^{S}\right)=\left[\left(K^{N}, L^{N}\right),\left(K^{S}, L^{S}\right)\right]$ be a partition of world factor endowments into the two countries, so that $\bar{K}=K^{N}+K^{S}$ and $\bar{L}=L^{N}+L^{S}$.

In the context of trade, we model better institutions in the North by assuming $\phi^{N}<\phi^{S}$ : in the North a lower fraction of $K$ becomes specific to the $M$-sector production unit, or, equivalently, contracts are less incomplete there. ${ }^{8}$

How can we determine the pattern of production and trade? Differences in institutional quality act in a way similar to a Ricardian productivity difference in the $M$-sector to generate comparative advantage and trade. It turns out that the trade equilibrium can be analyzed using an approach akin to the Davis (1995) Heckscher-Ohlin-Ricardo model. The starting point of the analysis is the integrated equilibrium, which is the resource allocation that results under perfect factor mobility. It is obtained by solving for the equilibrium of a closed economy characterized by the world factor endowment $\bar{V}$.

The key insight of the Davis model is that if one country can produce one of the goods

\footnotetext{
${ }^{8}$ This modeling assumption needs some justification, because it may seem counterfactual. After all, in this type of model the parameter $\phi$ is traditionally thought of as rigidity of labor market institutions or power of unions. Under this interpretation, the North would be expected to have a higher $\phi$, because it is typically believed that unions in the North are stronger. Latest empirical evidence suggests that this conventional wisdom is not correct, however. Botero et al. (2005) show that labor market regulations are actually more restrictive in the South than the North.

More generally, we are interested in the role of quality of contract enforcement and property rights, and not in labor market institutions. The interpretation of $\phi$ as a quality of contracting institutions is still appropriate, however. Quality of contracts and property rights will affect employment relationships in ways other than through labor laws. In addition, institutional frictions in other relationships will affect both the production allocation and rewards to labor. For instance, the principal lesson from the papers by La Porta et al. is that institutions matter because managers or inside capital expropriate outside investors. An extension of the model to a setting in which managers expropriate the outside capital $(K)$ is straightforward and leaves all the results below unchanged. The basic model in this section can be thought of as a reduced form of a fuller model which includes managers, and in which the relevant difference between the North and the South is the degree to which the managers can expropriate the outside capital.
} 
more cheaply than the other at a common set of factor prices, in the integrated equilibrium only that country's production process will be used to produce that particular good. In the Davis model, the difference between countries is in Ricardian productivity. Here, it arises instead because the North's less incomplete contracts allow it to sell the $M$-good at a strictly lower price. This is immediate from equation (7): the price at which the $M$-good can be produced under the Northern institutions is strictly less than the price when the Southern institutions are used:

$$
p_{M} y=w+\left(1+\phi^{N}\right) r x<w+\left(1+\phi^{S}\right) r x,
$$

as $\phi^{N}<\phi^{S}$. Therefore, in the integrated equilibrium, only the North's institutions will be used to produce the $M$-good. To complete the notation, denote by $\bar{V}(i)=[\bar{L}(i), \bar{K}(i)]$ the integrated equilibrium factor allocations in industry $i=K, L, M$.

From the integrated equilibrium production pattern we can construct a set of partitions of world factor endowments into countries called the Factor Price Equalization (FPE) Set. Following Helpman and Krugman (1985) and Davis (1995), we define the FPE set as follows:

Definition: Let $\eta_{i j}$ denote the share of the integrated equilibrium production of good $i$ that comes from country $j$. Then, the Factor Price Equalization set (FPE) is a set of partitions of the world factor endowments into countries defined by:

$$
\begin{aligned}
F P E= & \left\{\left(V^{N}, V^{S}\right) \mid \exists \eta_{K, N}, \eta_{L, N}, \eta_{K, S}, \eta_{L, S} \geq 0,\right. \text { such that } \\
& \eta_{K, N}+\eta_{K, S}=1, \eta_{L, N}+\eta_{L, S}=1, \eta_{M, N}=1, \eta_{M, S}=0, \\
& \left.V^{j}=\sum_{i} \bar{V}(i) \text { for } j=N, S\right\} .
\end{aligned}
$$

This definition says that the two countries' factor endowments belong to the FPE set when i) the North has enough of both factors to produce the entire integrated equilibrium world quantity of the $M$-good; and ii) the integrated equilibrium production of the $K$-and $L$-goods can be allocated between the two countries while keeping all factors fully employed. The FPE set is significant because when country endowments belong to it, the integrated equilibrium world resource allocations and prices are replicated purely through trade, as we state formally in the proposition below. ${ }^{9}$

Proposition 1: When the North has superior institutions, $\phi^{N}<\phi^{S}$, and $\left(V^{N}, V^{S}\right) \in$ FPE, the trade equilibrium world resource allocation, factor prices, and goods prices repli-

\footnotetext{
${ }^{9}$ We must use the term FPE with caution here. Factor rewards are equalized across countries in each sector, but in our model they differ across sectors. Thus, relative factor rewards across countries will be determined by which sectors operate in which countries. Nevertheless, the FPE set still has the useful feature that for appropriate factor endowments it allows us to analyze the trade outcomes by first constructing the integrated equilibrium.
} 
cate those of the integrated equilibrium. Therefore, in the trade equilibrium, only the North produces the $M$-good.

This result implies that in order to analyze the trade outcomes, we need to do little more than solve for the integrated equilibrium. Figure 1 illustrates the analysis. The sides of the box represent the world factor endowments. Any point in the diagram can represent a division of the world factor endowments into countries, where the North's endowments are measured from $O^{N}$, and the South's from $O^{S}$. The shaded area represents the FPE set. Since in the integrated equilibrium only the Northern institutional setting will be used in production of the $M$-good, country endowments can only belong to the FPE set if the entire integrated equilibrium production of the $M$-good can be accommodated in the North. This is the case, for example, at point $A$.

Let $V^{j}(i)=\left[L^{j}(i), K^{j}(i)\right]$ be the trade equilibrium use of factors in industry $i$ and country $j$. The pattern of production is graphically illustrated in Figure 2 for the factor endowments at point $A$. While in autarky the $M$-good was produced in both countries, under trade the South stops producing $M$ altogether, and now its entire factor endowment is dedicated to production of the $K$-good and the $L$-good. In the North the amount of the labor force in the $M$-sector increases to accommodate the entire world demand.

\subsection{Institutional Comparative Advantage and Gains from Trade}

We now come to the first key result of the paper, which is the analysis of gains from trade when institutional differences are the source of comparative advantage. To establish an expression for gains from trade, let $\left\{p_{K}^{N}, p_{L}^{N}, p_{M}^{N}, r^{N}, w^{N}, E^{N}\right\}$ and $\left\{p_{K}^{S}, p_{L}^{S}, p_{M}^{S}, r^{S}, w^{S}, E^{S}\right\}$ denote the autarky equilibria in the North and South respectively, and let $\left\{p_{K}^{T}, p_{L}^{T}, p_{M}^{T}, r^{T}, w^{T}, E^{T}\right\}$ be the values that describe the trade equilibrium. The trade values are obtained by solving for the integrated equilibrium, and thus $E^{T}$ is the fraction of the worldwide labor force employed in the $M$-sector, which we know from the discussion above is located entirely in the North.

The assumptions we made on the utility function imply that welfare is proportional to real income. Since we use the price of the optimal consumption basket as the numeraire, the prices that characterize both autarky and trade equilibria are real. The gains from trade are thus expressed as the difference in factor rewards between trade and autarky.

In autarky, the welfare of $K$ in country $i$ is simply $r^{i} K^{i}$. The welfare of $L$ is the sum of rewards to labor in the $L$ - and $M$-sectors. In the former, each unit of labor receives $w^{i}$. In the latter, the reward to labor includes some rents, and is given by equation (11). Putting 
the two together gives the following expression for $L$ 's autarky welfare in country $i$ :

$$
w^{i} L^{i}+\phi^{i} r^{i} x E^{i} L^{i}
$$

Let us now focus on the gains from trade that come purely from institutional comparative advantage. To do so, we consider the simplest case in which there are no factor proportions differences. Note that even with identical factor proportions, there is trade in our model, and there are gains and losses from trade. We state the relevant Propositions for the South and the North in turn, and explore the intuition behind the results.

\subsubsection{The South}

From the discussion above, it follows that the South's total welfare in autarky can be expressed as:

$$
r^{S} K^{S}+w^{S} L^{S}+\phi^{S} r^{S} x E^{S} L^{S}
$$

while welfare under trade is:

$$
r^{T} K^{S}+w^{T} L^{S}
$$

The gains from trade to the South are therefore the latter minus the former:

$$
r^{T} K^{S}+w^{T} L^{S}-\left(r^{S} K^{S}+w^{S} L^{S}+\phi^{S} r^{S} x E^{S} L^{S}\right)
$$

Proposition 2: Suppose trade takes place between North and South, whose factor endowments $\left(V^{N}, V^{S}\right) \in F P E$, and factor proportions are identical, $\frac{K^{N}}{L^{N}}=\frac{K^{S}}{L^{S}}$. The South's institutional comparative advantage driven gains are given by:

$$
\left[\left(r^{T}-r^{S}\right) K^{S}+\left(w^{T}-w^{S}\right) L^{S}\right]-\phi^{S} r^{S} x E^{S} L^{S}
$$

The first term, $\left[\left(r^{T}-r^{S}\right) K^{S}+\left(w^{T}-w^{S}\right) L^{S}\right]$, is positive, as $r^{T}>r^{S}$ and $w^{T}>w^{S}$. It is decreasing in $\phi^{N}$ and increasing in $\phi^{S}$. Furthermore, $\lim _{\phi^{N} \rightarrow \phi^{S}}\left[\left(r^{T}-r^{S}\right) K^{S}+\left(w^{T}-w^{S}\right) L^{S}\right]=$ 0 .

The second term, $\phi^{S} r^{S} x E^{S} L^{S}$, is positive and does not depend on $\phi^{N}$. It is increasing in $\phi^{S}$ for low enough $\phi^{S} \geq 0$.

The first term in the expression for gains from trade, $\left[\left(r^{T}-r^{S}\right) K^{S}+\left(w^{T}-w^{S}\right) L^{S}\right]$, represents the efficiency gain to the South from no longer using its institutions to produce the $M$-good. As we stressed in the discussion on the consequences of incomplete contracts, in general equilibrium unresolved specificity in the $M$-sector depresses $w$ and $r$ in order to generate sufficient surplus in production and induce the expropriated factor to enter the 
$M$-sector (see equation 7). Better institutions then imply lower unresolved specificity and therefore higher equilibrium $w$ and $r$.

The second term, $\phi^{S} r^{S} x E^{S} L^{S}$, represents the loss of rents that occurs because the $M$ sector disappears in the South. It has been known since at least Haberler (1950) and Hagen (1958) that when factor rewards differ across sectors, there will be gains (losses) from trade from the expansion (contraction) of sectors with higher factor rewards. Our contribution here is to demonstrate that such an outcome arises when contract incompleteness leads to segmented factor markets (a result due to Caballero and Hammour, 1998), and comparative advantage comes from institutional differences. ${ }^{10}$ In this model, a country is no longer indifferent as to which sectors are active under trade. Superior institutions allow the North to capture the more desirable sector, which disappears in the South.

Proposition 2 states that the gains from trade to the South always increase in the quality of the North's institutions. The South's own institutions have an ambiguous effect on the South's gains from trade: on the one hand worse institutions in the South imply that the efficiency gain from trade with the North, $\left[\left(r^{T}-r^{S}\right) K^{S}+\left(w^{T}-w^{S}\right) L^{S}\right]$, is greater for a given $\phi^{N}$. On the other hand, a higher $\phi^{S}$ may also increase the amount of autarky rents that the South stands to lose due to trade opening.

The Proposition highlights the circumstances under which the South's net gains from institutional comparative advantage driven trade are positive and negative. Note that the first, positive term in the gains from trade expression vanishes as institutions in the two countries converge, $\phi^{N} \rightarrow \phi^{S}$. This is intuitive: the first term is the efficiency gain from using the North's institutions to produce the $M$-good under trade. Naturally, it will be lower if the North's institutions are not much different from the South's, and will disappear in the limit as institutional differences vanish. On the other hand the second term is always strictly different from zero as long as $\phi^{S}>0$. Thus, when both countries' institutions are imperfect, and the North's are better by an exceedingly small $\varepsilon$ : $\phi^{S}=\phi^{N}+\varepsilon>0$, in the South the institutional comparative advantage driven net gains will be negative.

On the other hand, suppose that the North achieved perfect institutions: $\phi^{N}=0$. Under

\footnotetext{
${ }^{10}$ The implicit assumption is that even though workers are strictly better off in the $M$-sector, they do not expend real resources competing for these jobs. Allowing for this possibility does not qualitatively alter the results, provided that the $M$-sector rents are not dissipated completely. Complete rent dissipation occurs when the total expenditure by competing agents is equal to the total size of the $M$-sector rents. It can be ruled out by some relatively innocuous assumptions. For example, rents are not completely dissipated when agents are risk averse, or when agents differ in how much they value being in the $M$-sector. The latter could occur, for instance, if joining the $M$-sector is associated with dislocation (moving to the city), and agents differ in their disutility from it. For a detailed discussion of conditions under which complete rent dissipation breaks down, see Hillman (1989, pp. 58-72).
} 
trade, there is no longer market segmentation, and the first-best levels of factor prices are achieved in all countries and sectors. In this case, the first term dominates and the net welfare gain is positive. Opening to trade with the North implies that the South reaches the first-best level of aggregate welfare, entirely escaping the costs of its weak institutions. More generally, better institutions in the North make it more likely that the South's net gains are positive.

We can also discuss the net gains for individual factors. Capital wins unambiguously, because $r^{T}>r^{S}$. Labor experiences conflicting effects: though $w^{T}>w^{S}$, it is also the factor losing rents. As long as the institutional comparative advantage based gains from trade are negative, we can say with certainty that $L$ loses from trade as well. On the other hand, when the overall institutions-based gains from trade are positive, it is still possible for $L$ to lose from trade. For instance, when $\phi^{N}=0$ and the aggregate welfare is at the first-best level, $L$ may still lose from opening to trade, as it can no longer earn rents in the $M$-sector.

We summarize the discussion graphically in Figure 3. It depicts the ranges of parameter values $\left(\phi^{N}, \phi^{S}\right)$ under which the South overall net gains are negative, as well as those under which the South overall gains, but $L$ in the South loses. We maintain the assumption that $\phi^{N}<\phi^{S}$, and thus the area above, and including, the 45-degree line is ignored.

\subsubsection{The North}

We can write the North's autarky welfare as

$$
r^{N} K^{N}+w^{N} L^{N}+\phi^{N} r^{N} x E^{N} L^{N}
$$

and its trade welfare as

$$
r^{T} K^{N}+w^{T} L^{N}+\phi^{N} r^{T} x E^{T} \bar{L}
$$

In order to focus solely on the effects of institutions, suppose once again that North and South have the same $\frac{K}{L}$-ratio, and that after opening to trade we are in the FPE set. The Proposition below states formally the features of the North's gains from trade.

Proposition 3: Suppose trade takes place between North and South, whose factor endowments $\left(V^{N}, V^{S}\right) \in F P E$, and factor proportions are identical, $\frac{K^{N}}{L^{N}}=\frac{K^{S}}{L^{S}}$. The North's institutional comparative advantage driven gains are given by:

$$
\phi^{N} r^{N} x E^{N}\left(\bar{L}-L^{S}\right)
$$

The North's gains from trade are always positive, and do not depend on $\phi^{S}$. They increase in $\phi^{N}$ for low enough values of $\phi^{N}$. 
The North gains from institutional comparative advantage purely through expansion of the high-paying $M$-sector. The expression for gains from trade in the Proposition is so simple because absent factor proportions differences, the factor prices are the same under trade as in autarky in the North $\left(w^{T}=w^{N}\right.$ and $\left.r^{T}=r^{N}\right)$. Nonetheless, here the North gains from trade even if the underlying factor rewards are unchanged.

What is intriguing about this Proposition is that the North's gains from trade increase in $\phi^{N}$, at least for low enough values of $\phi^{N}$. Worse institutions in the North can lead to larger gains from trade! This statement is of course distinct from, and consistent with, the result that better institutions improve both autarky and trade welfare in the North. The key intuition is that the gains from trade in the North come from an increase in the rents $L$ is earning in the $M$-sector. For low enough $\phi^{N}$, we show that those rents are increasing in $\phi^{N}$.

\subsubsection{Discussion}

The analysis readily incorporates factor endowment differences between countries. Proposition 1 defines the pattern of production and trade for any two countries whose factor endowments belong to the FPE set. With factor proportions differences, there is an extra term in the expressions for gains from trade. Let us separate the gains from trade that come from differences in factor abundance and institutional differences. For instance, let us define $\tilde{w}$ and $\tilde{r}$ to be the factor prices that obtain under autarky in a hypothetical country characterized by the South's factor endowments $\left(L^{S}, K^{S}\right)$, and the North's institutions $\phi^{N}$. Then, the gains from trade to the South can be written as

$$
\underbrace{\left(r^{T} K^{S}-\tilde{r} K^{S}\right)+\left(w^{T} L^{S}-\tilde{w} L^{S}\right)}_{\text {Factor-Proportions Based Gains }}+\underbrace{\left(\tilde{r} K^{S}+\tilde{w} L^{S}\right)-\left(r^{S} K^{S}+w^{S} L^{S}+\phi^{S} r^{S} x E^{S} L^{S}\right)}_{\text {Institutional Comparative Advantage Based Gains }} .
$$

In this way, the total gains from trade can be decomposed into two separate parts. The first term represents the gains from trade between two countries with identical institutions but (possibly) differing factor proportions. When $\frac{K^{S}}{L^{S}}=\frac{K^{N}}{L^{N}}$, factor prices are the same in autarky and trade $\left(\tilde{r}=r^{T}\right.$ and $\left.\tilde{w}=w^{T}\right)$, and the first term disappears. The second term represents the gains from trade that come purely from institutional differences, and is the subject of Proposition 2. Thus, for the South factor proportions-based gains are combined with institutions-based gains in a straightforward way.

We can thus contrast the predictions of factor proportions theory and institutional comparative advantage regarding how factor rewards change as a result of trade opening between a developed country and a developing one. The most common way of thinking 
about this issue is to assume that the developed country is relatively capital abundant. This paper suggests another way, which seems to be at least as relevant empirically: the developed country has better institutions, which allow the factors to be allocated more efficiently. In the capital-scarce South, the factor proportions model predicts that returns to capital decrease and returns to labor increase when it opens up to trade with the capitalabundant North (see, for example, Dixit and Norman, 1980). In the North the opposite occurs: wages go down but return to capital goes up.

The effects of institutional differences are superimposed on that, and go in the opposite direction. In the South, the relatively abundant labor's gains are eroded by the loss of the $M$ sector, while Southern capital benefits from opening to trade. On the other hand, the return to capital in the North remains unchanged, whereas rewards to labor increase. ${ }^{11}$ Thus, institutional differences could be a countervailing force to the standard factor proportions driven price changes that result from trade.

We can also note what institutional comparative advantage implies about factor price convergence. In the pure Heckscher-Ohlin world, factor rewards converge perfectly by virtue of being in the Factor Price Equalization Set. In the present case, we once again observe conflicting effects. Rewards to capital are equalized. Trade affects relative rewards to labor in two ways. First, in the South the base wage $w$ is pulled up to the level of the North, a force towards convergence. On the other hand, however, a higher share of the Northern labor force is employed in the high-paying $M$-sector, while in the South it goes to zero. Comparing the mean wages under autarky and trade, we can say unambiguously that the average wage goes up in the North, while it may go up or down in the South. The same forces that erode the gains from trade in the South can also produce factor price divergence resulting from trade.

\subsubsection{Aside: Comparison to the Ricardian View of Institutional Comparative Advantage}

To further explore the sources of the welfare results presented above, in this subsection we contrast the incomplete contracts approach to modeling institutions with a reduced-form approach more traditional in trade theory, which we refer to as the Ricardian view. Under the Ricardian view, imperfect institutions are modeled simply as a productivity difference in the $M$-good sector. Suppose in fact that once a production unit has been formed and

\footnotetext{
${ }^{11}$ It is important to note that this is a direct consequence of assuming that contract incompleteness matters for capital and not for labor $\left(\phi^{K}>0, \phi^{L}=0\right)$. Naturally, results are reversed, and more in line with the standard theory if one makes the opposite assumption. We hold the view that the assumption we made is more relevant empirically.
} 
production had taken place, a fraction $\tau$ of the output is lost due to imperfect institutions. As the parameter $\tau$ is meant to capture institutional quality, it is natural to think of better institutions as lower values of $\tau$. Profit maximization in the $M$-good industry then implies:

$$
p_{M}(1-\tau) y=w+x r
$$

which simply says that price equals unit cost. Equation (12) replaces (7) as one of the equilibrium conditions (2) through (10). Note that in equilibrium under the Ricardian view there will not be any rents nor factor rewards differences across sectors.

To address the issue of trade in the presence of institutional differences, suppose that fractions $\tau^{N}$ and $\tau^{S}$ of the $M$-good produced in the North and the South, respectively, are lost due to institutional imperfections, with $\tau^{N}<\tau^{S}$. Since this set of assumptions is equivalent to a Ricardian productivity difference in the $M$-sector, the model becomes simply a special case of Davis (1995) Heckscher-Ohlin-Ricardo model we referred to earlier. Proceeding in similar steps, we can solve for the integrated equilibrium in which only the Northern technology will be used in $M$-good production. There exists an FPE set, in which the integrated equilibrium prices and production patterns are replicated. This requires, just as above, the factor endowments to be such that the entire integrated equilibrium quantity of $M$ can be produced in the North. Diagrammatically, the FPE set and the pattern of production look exactly the same as under the incomplete contracts view (Figures 1 and 2). The South stops producing $M$ altogether, and in the North the size of the $M$-sector grows from $E^{N} L^{N}$ to $E^{T} \bar{L}$ - the entire integrated equilibrium value of production.

Just as above, the assumptions we made on the utility function imply that welfare is proportional to real income, and the prices characterizing the equilibrium are real. Thus, in autarky, the welfare of $L$ and $K$ in country $i$ is simply $w^{i} L^{i}$ and $r^{i} K^{i}$, and the aggregate welfare is simply $w^{i} L^{i}+r^{i} K^{i}$. Note that there is no segmentation of factor markets here, and thus the production mix, namely that the $M$-sector no longer operates in the South, does not matter for the welfare expressions.

To maintain the closest parallel to our treatment of the incomplete contracts approach, we focus solely on the effects of institutions, and suppose that North and South have the same $\frac{K}{L}$-ratio. Proceeding in similar steps to the analysis above, we can show that the goods and factor prices under trade are the same as the Northern autarky prices: $w^{T}=w^{N}$ and $r^{T}=r^{N}$. This implies that welfare in the North is unchanged with trade and the gains accrue entirely to the South, where welfare of both factors unambiguously rises: $w^{T}>w^{S}$ and $r^{T}>r^{S}$. The South loses all of its $M$-sector, but factor rewards increase, as it is able to take advantage of the superior Northern institutions purely through trade. 
To summarize, the welfare results obtained under the Ricardian view are all but the opposite to those under the incomplete contracts view. This implies that when institutions lead to distortions in production and factor market segmentation, modeling them as simple productivity differences misses crucial effects of institutional comparative advantage on welfare.

\subsection{Equilibrium Outside of the FPE Set}

The simple structure of the model makes it easy to analyze equilibria that result when factor endowments lie outside of the FPE set. The key simplifying feature is that two of the goods are produced with only one of the factors. Thus, the rewards that factors can earn in the $L$ - and $K$-sectors, $w$ and $r$, are equalized under trade for any set of endowments:

$$
\begin{aligned}
& w_{N}^{T}=b p_{L}^{T}=w_{S}^{T} \\
& r_{N}^{T}=a p_{K}^{T}=r_{S}^{T},
\end{aligned}
$$

Outside of the FPE set there are several cases to consider. First, when the relative factor endowments are such that the North can produce a quantity of the $M$-good sufficiently close to the integrated equilibrium quantity, the South does not produce the $M$-good. This is because as long as $\phi^{N}<\phi^{S}$, and the individual rationality condition for $K$ in the North holds with equality:

$$
p_{M}^{T} y=w^{T}+\left(1+\phi^{N}\right) x r^{T}
$$

the South cannot produce $M$ :

$$
p_{M}^{T} y<w^{T}+\left(1+\phi^{S}\right) x r^{T} .
$$

Such a case is illustrated in Figure 4 for a set of endowments at the point $C$. In this case the North produces only $K$ and $M$, and the entire labor force is employed in the $M$-sector, earning rents. The production of the $M$-good is lower here than under FPE, and thus its relative price is higher. Nevertheless, the South cannot start its own $M$-sector industry, and its entire endowment is dedicated to producing the $K$ - and $L$-goods. More generally, if factor endowments are sufficiently dissimilar, or the North is sufficiently small relative to the South, some production of the $M$-good is possible in the South under trade. For wide ranges of parameter values outside of $\mathrm{FPE}$, the most important effect of the model is still present. Compared to autarky, the high-paying $M$-sector shrinks in the South.

Note, however, that a variety of outcomes are possible in general when one steps out of the FPE set. For instance, in a richer model in which the $K$-and $L$-goods use both 
factors, and there can be some factor substitution in production of those goods, it is possible that large enough differences in factor endowments can reverse institutional comparative advantage. For example, if the South is sufficiently labor abundant, its wage will be lower than the Northern wage. This wage difference may more than offset the North's institutional comparative advantage and enable the South to specialize in the $M$-good.

This discussion makes clear the boundaries of the results presented so far in this paper. The paper examines the case in which institutional comparative advantage is the salient source of trade: a country with better institutions specializes in the institutionally intensive goods. If institutional comparative advantage is more than offset by some other force - be it factor price differences, productivity differences, or something else - we will not be able to make simple statements connecting a country's institutional quality to its gains from trade. However, the key insight of this paper would still apply in a richer model with many other effects and sources of comparative advantage. Incomplete contracts create segmented markets, and segmentation generates its own source of gains and losses from trade. One would only need to determine where the high-paying sectors expand or contract as a result of trade opening.

\section{$3 \quad$ Empirical Evidence}

The basic two-country model we described in the previous section illustrates the consequences of institutional comparative advantage. When countries open to trade, the institutionally superior country will export the institutionally dependent good. This section aims to test this prediction. The empirical strategy exploits variation in institutional quality across countries and dependence on institutions across industries. We embed the test of institutional comparative advantage in the factor content of trade specification of Romalis (2004). Using data on US imports disaggregated by industry and country, we provide evidence that countries with better institutions capture larger import shares in more institutionally dependent industries.

\subsection{Specification}

Because of its simplicity, the basic model we developed above delivers the extreme prediction that the institutionally inferior country does not produce or export the institutionally dependent good, $M$. It is also not useful to talk about import shares in a two-country model. This section outlines an extension of the basic model to derive the predicted relationship between import shares, industry-level institutional dependence, and country-level 
institutional quality.

We modify the basic model in three ways. First, we now suppose there are $J$ countries. Second, each country produces its own unique variety of the $M$-good. We adopt the Armington assumption: varieties of the $M$-good produced in each country are imperfect substitutes. In particular, while the preferences across the $K-, L$-, and $M$-goods are still given by equation (1), now $C_{M}$ is interpreted as a CES aggregate of the $M$-good varieties from each country:

$$
C_{M}=\left[\sum_{j=1}^{J} C_{M j}^{\frac{\sigma-1}{\sigma}}\right]^{\frac{\sigma}{\sigma-1}} .
$$

We assume that $\sigma>1$, that is, the varieties from different countries are gross substitutes. In any country $l$, demand for country $k$ 's variety of the $M$-good is given by: ${ }^{12}$

$$
C_{M k}^{l}=\frac{p_{M k}^{-\sigma}}{\left(\sum_{j=1}^{J} p_{M j}^{1-\sigma}\right)^{-\frac{\sigma}{1-\sigma}}} C_{M}^{l} .
$$

The total value of country l's $M$-sector imports from all countries is:

$$
I_{M}^{l}=\sum_{\substack{j=1, j \neq l}}^{J} p_{M j} C_{M j}^{l}
$$

The share of country $k$ 's imports in the $M$-sector is then:

$$
s_{M k}^{l}=\frac{C_{M k}^{l}}{I_{M}^{l}}=\frac{p_{M k}^{1-\sigma}}{\sum_{\substack{j=1, j \neq l}}^{J} p_{M j}^{1-\sigma}} .
$$

The third modification of the model is motivated by our objective to exploit crossindustry differences in institutional dependence. In our empirical estimation, we will proxy for institutional dependence with measures of product complexity based on intermediate good use. Intuitively, institutions are more important to industries that require joining of a relatively large number of parties to production, simply because there are more relationships that are potentially distorted due to imperfect institutions.

To illustrate the link between product complexity and institutional dependence, we modify the production technology of the $M$-good to include multiple intermediates, in the

\footnotetext{
${ }^{12}$ See Helpman and Krugman (1985, pp. 117-118).
} 
spirit of Blanchard and Kremer (1997). ${ }^{13}$ In particular, suppose that in addition to $K$ and $L$, production of the $M$-good requires the use of $(n-1)$ intermediates, organized along a chain of production. For simplicity, we assume that each intermediate good producer's outside option is zero. The producer of the first intermediate joins with $x$ units of $K$ to produce one unit of intermediate 1, and because of contracting imperfections, a share $\phi$ of $K$ 's investment becomes specific to the relationship. Once that unit is produced, the first producer joins with a second intermediate producer, and again a fraction $\phi$ of the value of the first intermediate good becomes specific to producer 2 , and so on. The $(n-1)$-th intermediate producer joins with $L$ to produce the final $M$-good, again becoming partly specific to the relationship. In each case, we make our usual assumption that the surplus is divided equally between the parties.

What is the $M$-good price at which production is feasible in this industry? We can solve for it by working backwards from the final goods production stage and using the same reasoning we applied in the no-intermediates case of the basic model. The key is that each time a party to production makes a specific investment, its participation constraint must be satisfied. In equilibrium, if production takes place, $p_{M}$ must satisfy:

$$
p_{M} y=w+(1+\phi)^{n} r x
$$

an analog to equation (7). This equation shows that if relationships between parties joining for production are subject to frictions $(\phi>0)$, the price of the final good will be increasing in the product complexity, $n$. This means that for a given level of institutional quality, the amount of $M$-good produced in equilibrium will be lower the higher is the $M$-good's complexity. Also, for a given level of $M$-good's product complexity, a country with better institutions (lower $\phi$ ) will enjoy a higher level of $M$-good production.

Combining equations (13) and (14), suppose that country $k$ has a level of institutional quality $\phi^{k}$. Plugging $p_{M k}$ into equation (13), taking logs, and making a further simplifying assumption that $w$ is close to zero, ${ }^{14}$ we get the following approximate relationship between country $k$ 's share of imports to country $l$ :

$$
\ln \left(s_{M k}^{l}\right) \approx(1-\sigma) n \ln \left(1+\phi^{k}\right)+D_{l k} .
$$

Using the assumption that $\sigma>1$, we can thus establish that countries with inferior institutions (higher $\phi$ ) will have lower import shares in the institutionally intensive sector

\footnotetext{
${ }^{13}$ Costinot (2005) provides a related treatment, in which he endogenizes the optimal number of parties to production, given the number of production stages.

${ }^{14}$ Alternatively, we could assume that the labor intensity in the $M$-sector production is very low.
} 
$(M)$. Furthermore, this effect will be stronger the more institutionally intensive is the $M$ sector (higher $n$ ). The last term, $D_{l k}$, summarizes the features of the trading countries, as well as characteristics of the $M$-sector, such as factor intensity.

Our empirical analysis aims to test this prediction using import data for the US. Of course, any empirical test of the impact of institutions on trade patterns must control for other determinants of trade. Romalis (2004) developed a simple empirical model which shows that endowments of skilled labor, unskilled labor, and capital are important in explaining US import patterns across countries and industries. We augment his model to include institutional intensity. Specifically, we estimate:

rel_share $i_{i c}=\alpha+\beta_{1}$ inst_dep $_{i} *$ inst $_{c}+\beta_{2}$ skint $_{i} *$ skill $_{c}+\beta_{3}$ capint $_{i} *$ capital $_{c}+\gamma_{c}+\delta_{i}+\varepsilon_{i c}$,

where $i$ indexes industries and $c$ countries. In particular, rel_share $e_{i c}$ is country $c$ 's US import share in sector $i$, normalized as we will explain below. Industry-level variables capint $3_{i}$ and skint $_{i}$ are measures of capital and skill intensity, and country-level variables capital $_{c}$ and skill $_{c}$ measure capital and skill abundance. To these we add an industry-level measure of institutional dependence (inst_dep $p_{i}$ ), and a country-level measure of institutional quality $\left(\right.$ inst $\left._{c}\right)$. Motivated by equation (15), we are most interested in the coefficient on the institutions interaction term, $\beta_{1}$. A positive estimate of $\beta_{1}$ would provide evidence consistent with the predictions of the model: countries with better institutions capture higher trade shares in institutionally intensive sectors. Our estimation includes a full set of both country and industry dummies.

\subsection{Data Sources and Variable Definitions}

We use data on the 1998 US imports classified by 4-digit SIC industry and country of origin, available on the National Bureau of Economic Research website. Overall, there are trade data for 177 countries and 389 industries. The left hand side variable that we use, rel_share $i_{i c}$, is country $c$ 's trade share in sector $i$, divided by the average share of country $i$ in US imports. This is done to make the coefficient comparable across countries and is meant to account for country size and the closeness of its trade relationship to the United States. $^{15}$

\footnotetext{
${ }^{15} \mathrm{~A}$ log-transformation cannot be used because many of the import shares are 0. Dropping all observations in which import shares are zero and estimating a specification with $l o g\left(\right.$ rel_share $\left._{i c}\right)$ as the dependent variable improves both the fit of the regression and the significance of the coefficient of interest. Alternatively, estimating a logit in which the dependent variable is an indicator of whether or not a given country exports in each sector yields highly significant coefficients of interest.
} 
Our empirical strategy requires a variable that captures industry-level institutional dependence. There is no well-accepted industry-level index of institutional dependence, and, indeed, the very notion is much more vague than, for example, capital intensity. Consistent with the model outlined in the previous subsection, we proxy for inst_dep $i$ with a measure of product complexity. In particular, we use the Herfindahl index of intermediate input use, computed from the US Input-Output Use Table for $1992 .{ }^{16}$

The Herfindahl index has been used to measure product complexity and proxy for institutional dependence in the literature (e.g. Blanchard and Kremer 1997, Cowan and Neut 2002). The rationale for using it rather than simply the number of intermediates employed in production is the following. If intermediate input use is dominated by one or two inputs (high concentration), and all the other intermediates are used very little, then what really matters to the final good producer is the relationship it has with the largest one or two suppliers. The scope for and importance of expropriation by suppliers of minor inputs is probably much smaller than by important suppliers. Thus, simply taking the number of intermediates may give excessive weight to insignificant input suppliers and overestimate the effective reliance on institutions. Because the Herfindahl index increases with concentration, we multiply it by -1 in order to have a measure that increases in institutional intensity.

We control for factor intensity differences in production coupled with factor endowment differences across countries. In particular, we take as a baseline a three-factor model, with unskilled labor, skilled labor and capital. Capital intensity (capint3) of an industry is measured as one minus the share of total compensation in value added. Skilled labor intensity (skint3) is then the ratio of nonproduction workers to total employment multiplied by the total share of labor in value added, $(1-$ capint 3$)$. Unskilled labor is the third factor. ${ }^{17}$ These are calculated using the US Manufacturing database maintained by the National Bureau of Economic Research and US Census Bureau's Center for Economic Studies for 1992. While all industry-level measures are calculated using US data, the estimated coefficients are interpretable as long as there are no factor intensity or institutional intensity reversals.

Country-level measures of skilled labor and capital abundance are adopted from Hall and Jones (1999). Finally, to measure the quality or contracting institutions we use the index of rule of law developed by Kaufmann, Kraay and Mastruzzi (2005). ${ }^{18}$ This measure

\footnotetext{
${ }^{16}$ We use this and other measures intermediate input use concentration following the work of Cowan and Neut (2002). We are grateful to Kevin Cowan for sharing the Stata code that generates these measures.

${ }^{17} \mathrm{~A}$ measure of unskilled labor intensity is not included in the regression because by construction it is spanned by the constant term, capint3, and skint3.

${ }^{18}$ Our results are robust to using alternative measures of institutional intensity, such as those coming from the International Country Risk Guide, World Bank's Doing Business Indicators, or the Heritage Foundation.
} 
is meant to capture the quality of contract enforcement, security of property rights, and predictability of the judiciary. In other words, it is the closest empirical counterpart to the kinds of institutions we model above. We take the average of this indicator over 1996, 1998, and 2000 (the database is compiled every two years). The index ranges between -2.5 (lowest institutional quality) and 2.5.

The final sample contains 116 countries and 389 industries. Appendix Table A1 lists some of the least and most institutionally intensive sectors. Industry-level variables are summarized in Appendix Table A2. Our preferred measure of institutional dependence is slightly negatively correlated with capital intensity (correlation coefficient of -0.131), and positively, but not strongly, correlated with skill intensity (correlation of 0.277). Summary statistics for country-level variables are given in Appendix Table A3. The countries for which all the necessary data are available are listed in Appendix Table A5.

\subsection{Results and Robustness}

The baseline estimate is presented in Column (1) of Table 1. The coefficient of interest is of the expected sign and highly significant. The effect is quantitatively important as well. In a country that moves from the 25 th to the 75 th percentile in institutional quality, the predicted relative import share in the good occupying the 25 th percentile in institutional intensity decreases by 0.07 , and the predicted relative import share in the good corresponding to the 75 th percentile in institutional intensity increases by 0.23 . The effect is quantitatively similar to the analogous effects in capital and skill intensity and abundance.

To ensure that we are really picking up the effect of institutions on trade, we now conduct a number of robustness checks. One obvious concern is whether the result is sensitive to our choice of institutional dependence variable. To address this, we use a set of alternative measures of institutional dependence. We start with two alternative indices of intermediate use concentration, the share of 20 largest intermediates in total intermediate good expenditure, and the Gini coefficient of intermediate good use. These work in a manner similar to the Herfindahl index, assigning a high institutional intensity to industries with dispersed and even intermediate use pattern, and low institutional intensity to industries in which intermediate use is concentrated. Next, we use a simpler measure, which is the number of intermediates used in production. As we discussed above, when some intermediates are insignificant, this measure will show a sector to be institutionally intensive even when effective contract intensity is low. All three of these measures are calculated using the 1992 US Input-Output Use Table. To use a completely different measure, we 
also calculate the ratio of investment to output. This proxies for institutional dependence if the holdup problem increases with the size of investment. Industries whose technology requires a higher investment to produce will have to rely on contract and property rights enforcement to a greater extent. This measure is calculated using the US Manufacturing database maintained by the National Bureau of Economic Research and US Census Bureau's Center for Economic Studies for 1992. Correlations between the Herfindahl index and the alternative indices of institutional intensity are presented in Appendix Table A4. These are always positive, ranging from 0.13 to 0.74 . Columns (2) through (5) of Table 1 present the results of using the alternative measures of institutional intensity. Regardless of the measure of institutional intensity used, we find a positive and statistically significant relationship between institutional intensity and trade shares.

Another concern might be that the institutional quality measure is a proxy for some other feature of countries with good institutions. For instance, perhaps the more institutionally intensive goods require higher endowments of skilled labor or capital. To address this issue, Table 2 presents results for several alternative specifications. First, we run our basic specification with a full set of interaction terms. Thus, for example, the Herfindahl index is interacted not only with institutional quality, but with skill and capital abundance as well. The results are presented in Column (1) of Table 2. While the coefficient on the Herfindahl index and institutional quality interaction term is virtually unchanged and still highly significant, the other two interaction terms involving the Herfindahl index are not significant. This suggests that institutional quality is relatively more important to production of complex goods than skill and capital abundance. It is also interesting to note that while the conclusions about the "institutional content of trade" are unchanged with the inclusion of cross-interaction terms, the significance of factor content of trade is eroded. In particular, while in the base specification exports of skill intensive goods were significantly correlated with country skill abundance, the interaction term of skill intensity and institutional quality seems to pick up all the significance. This suggests that institutional quality is relatively more important than skill abundance in generating exports of skill intensive goods.

To test robustness further, we expand the number of factors of production by including raw materials as one of the factors. The raw material intensity (matint4) is measured as the value of raw material inputs divided by the sum of raw materials and value added. Consequently, the skill and capital intensity in the four factor model are 
capint $4=$ capint $3(1-$ matint 4$)$ and $\operatorname{skint} 4=\operatorname{skint} 3(1-$ matint 4$)$, respectively. ${ }^{19}$ Raw materials abundance is proxied by the total land area divided by the total population, sourced from the World Bank World Development Indicators CD-ROM. Column (2) in Table 2 presents the results of estimating a four-factor model. Once again, the coefficient on the institutional intensity interaction term is very similar, and just as significant as in the three-factor specification. Finally, we estimate the four-factor model with all the cross-interactions, and present the results in Column (3) of Table 2. The coefficient on the institutional interaction term is slightly lower, but still significant at 5 percent level. There can also be concerns that our institutional intensity variable is in some way related to tradability. To make sure our results are not driven by bilateral distances between the US and its trading partners, Column (4) includes the interaction of institutional intensity with bilateral distance to the importing country. The distance data are taken from Centre d'Etudes Prospectives et d'Informations Internationales (CEPII). It is clear that including the distance interaction does not affect the significance of the main result.

Recent evidence suggests that countries with more developed financial markets tend to produce and export goods that rely more heavily on external finance (e.g. Beck, 2003). To control for financial comparative advantage, we construct a measure of industry financial dependence based on Compustat firm-level data, and following the methodology of Rajan and Zingales (1998). In particular, for each firm and each year, we define financial dependence as capital expenditure minus cash flow, divided by capital expenditure. We then average this measure for each firm over the period 1989-1998, and take the median across firms in each sector to create a sector-level index of financial dependence. ${ }^{20}$ We proxy for country-level financial development with the ratio of private credit by deposit money banks and other financial institutions to GDP for the period 1990-1998, sourced from Beck et al. (2000). Due to limited data availability, the resulting sample includes only 276 industries and 102 countries. Column (5) of Table 2 reports the results of controlling for financial comparative advantage alongside institutions in our base specification. We confirm that differences in financial development are a relevant determinant of trade patterns. Our conclusions regarding institutional comparative advantage are unchanged, as the coefficient of interest is similar in magnitude to the baseline estimate and still highly significant. Institutions affect trade patterns in ways that cannot be accounted for exclusively by differences

\footnotetext{
${ }^{19}$ Once again, the fourth factor, unskilled labor intensity, is implicit.

${ }^{20}$ The number of firms available in each 4-digit SIC sector is generally small, often just 1 or 2 firms. To create meaningful averages, we compute them at 3-digit SIC level. We then drop all observations which were created by averaging less than 10 firms. We are very grateful to Claudio Raddatz for providing us with the necessary firm-level data and helpful advice.
} 
in financial development.

Because institutional quality is highly correlated with the overall level of economic development, some other unobserved features of developed countries could be responsible for generating higher trade in institutionally intensive sectors. To control for the unobservables that are correlated with development, in Column (6) of Table 2 we estimate our model while interacting sector fixed effects with log PPP-adjusted per capita GDP from the Penn World Tables (Heston et al., 2002). Doing so allows the level of development to affect trade in each individual sector differentially in an unrestricted way. ${ }^{21}$ Our results are fully robust to this specification, and in fact the coefficient increases in magnitude compared to the baseline and remains significant at $1 \%$ level.

As another robustness check, we see whether the results are driven by certain subsets of the sample. Column (1) of Table 3 presents estimation results on a subsample that excludes the North, defined as industrial countries with per capita PPP-adjusted GDP of at least $50 \%$ of the US level. The list of countries belonging to the North is provided in Appendix Table A5. It is clear from Column (1) that the results are not driven simply by the North-South differences in import patterns. The coefficient of interest is actually greater in magnitude than in the full sample, and highly significant. Notice also that the coefficients on skill and capital interactions lose significance in the South-only sample, reinforcing the relative importance of institutions. We also perform estimation on the subsample that excludes SubSaharan Africa, and present the results in Column (2) of Table 3. The coefficient of interest is slightly lower than in the full sample, and still highly significant. The results are similarly unchanged when the South-East Asian economies are removed from the sample, as evidenced by Column (3). To check whether the results are driven by outlier industries, in Column (4) of Table 3 we estimate our base specification excluding the 10 most institutionally intensive industries. ${ }^{22}$ Doing so leaves the coefficients and their significance virtually unchanged.

\section{Conclusion}

Recent literature has greatly improved our understanding of the role of institutions in countries' economic performance. Given the emerging consensus regarding their primary importance, a natural question to ask is how do institutional differences affect trade out-

\footnotetext{
${ }^{21}$ Note that this is a more stringent specification than, for example, adding an interaction between institutional intensity and per capita GDP to the specification, as it adds an extra 389 regressors (same as the number of sectors in our sample).

${ }^{22}$ Virtually the same results are obtained if we drop the 20 most institutionally intensive sectors, as well as the 10 or 20 least institutionally intensive sectors.
} 
comes. This paper models institutional comparative advantage using the insights from the incomplete contracts literature, to reach several surprising conclusions. When institutions are the source of comparative advantage, the North gains the most from trade, while the South experiences conflicting effects. On the one hand, there is an efficiency gain from not using its own inferior institutions. On the other, the high-paying sectors disappear due to trade opening. Under some parameter values, the South may lose and factor rewards may diverge as a result of trade.

How relevant is the incomplete contracts view of institutions? We believe that it captures well the role of contracting imperfections between private parties that enter production relationships. A broader view of institutions may include, for instance, government expropriation and political instability, for which the Ricardian view is perhaps more accurate. Industries could also differ in the kinds of institutions they require. This paper argued that interactions between institutions and trade are important, and are likely to be quite nuanced. What kinds of effects prevail in which circumstances remains an open question.

\section{A Appendix: Proofs of Propositions}

Proof of Proposition 1: The proof follows the treatment in Helpman and Krugman (1985, p. 13-14). The FPE set is defined as a partition of the world factor endowments into countries such that every country can fully employ all of its factors using the integrated equilibrium techniques of production. To prove that trade replicates the integrated equilibrium factor prices, we observe that given the integrated equilibrium factor prices, every firm employs the integrated equilibrium techniques of production. Thus, by definition of the FPE set, under the integrated equilibrium factor prices, full employment prevails in each country without movements of factors across countries. Thus, under trade in goods but not factors, the world economy can produce the integrated equilibrium quantities of all the goods. Since, under the integrated equilibrium factor prices, the aggregate world income is also equal to the integrated equilibrium world income, and consumption shares are also the same, there is goods market clearing. Thus, such a resource allocation and set of factor and goods prices under trade are an equilibrium, which by construction replicates the factor prices of the integrated equilibrium.

Proof of Proposition 2: The discussion in the main text derives the expression for gains from trade. To prove the claims made about this expression, we observe that the South's autarky equilibrium is found by solving equations (2) through (10) using $\phi^{S}, K^{S}$, and $L^{S}$. From Proposition 1 we know that the trade equilibrium allocation is given by the solution to the same equilibrium equations, (2) through (10), using instead $\phi^{N}, \bar{K}$, and $\bar{L}$.

To prove the first set of claims, we can write out directly the expressions defining $r^{S}, w^{S}$, $r^{T}$, and $w^{T}$. In particular, a straightforward rearranging of equilibrium conditions yields the following expressions:

$$
r^{S}=\alpha \frac{\left[a\left(\frac{K^{S}}{L^{S}}-x E^{S}\right)\right]^{\alpha}\left[b\left(1-E^{S}\right)\right]^{\beta}\left[y E^{S}\right]^{\gamma}}{\left(\frac{K^{S}}{L^{S}}-x E^{S}\right)}
$$


and

$$
w^{S}=\beta \frac{\left[a\left(\frac{K^{S}}{L^{S}}-x E^{S}\right)\right]^{\alpha}\left[b\left(1-E^{S}\right)\right]^{\beta}\left[y E^{S}\right]^{\gamma}}{\left(1-E^{S}\right)} .
$$

With some manipulation, we can show that equilibrium $E^{S}$ is given implicitly by:

$$
\frac{\gamma}{E^{S}}=\frac{\beta}{1-E^{S}}+\frac{\alpha\left(1+\phi^{S}\right) x}{\frac{K^{S}}{L^{S}}-x E^{S}} .
$$

We can follow similar steps to solve for the trade values:

$$
\begin{aligned}
r^{T} & =\alpha \frac{\left[a\left(\frac{\bar{K}}{L}-x E^{T}\right)\right]^{\alpha}\left[b\left(1-E^{T}\right)\right]^{\beta}\left[y E^{T}\right]^{\gamma}}{\left(\frac{\bar{K}}{L}-x E^{T}\right)}, \\
w^{T} & =\beta \frac{\left[a\left(\frac{\bar{K}}{L}-x E^{T}\right)\right]^{\alpha}\left[b\left(1-E^{T}\right)\right]^{\beta}\left[y E^{T}\right]^{\gamma}}{\left(1-E^{T}\right)},
\end{aligned}
$$

and

$$
\frac{\gamma}{E^{T}}=\frac{\beta}{1-E^{T}}+\frac{\alpha\left(1+\phi^{N}\right) x}{\frac{\bar{K}}{\bar{L}}-x E^{T}} .
$$

Note that the factor prices (A.1)-(A.2) and (A.4)-(A.5) are a function of the $\frac{K}{L}$-ratio only, and not of the levels of $K$ and $L$. Note also that they do not depend directly on $\phi$, only indirectly through its effect on $E$. Since we assume that $\frac{K^{N}}{L^{N}}=\frac{K^{S}}{L^{S}}=\frac{\bar{K}}{L}$, the only difference between $r^{S}$ and $r^{T}$ will come from differences between $E^{S}$ and $E^{T}$, and same for $w^{S}$ and $w^{T}$. Taking the derivative of $w$ and $r$ with respect to $E$, it is immediate that $\frac{d r}{d E}>0$ and $\frac{d w}{d E}>0$. Therefore, if $E^{T}>E^{S}$, we know unambiguously that $w^{T}>w^{S}$ and $r^{T}>r^{S}$.

We can use a similar argument to establish that $E^{T}>E^{S}$. In particular, when $\frac{K^{N}}{L^{N}}=$ $\frac{K^{S}}{L^{S}}=\frac{\bar{K}}{\bar{L}}$, the only difference between (A.3) and (A.6) is in the value of $\phi$. Differentiating (A.3) implicitly with respect to $\phi$, we can show that $\frac{d E}{d \phi}<0$. Therefore, because $\phi^{N}<\phi^{S}$, we know that $E^{T}>E^{S}$.

To prove that $\left[\left(r^{T}-r^{S}\right) K^{S}+\left(w^{T}-w^{S}\right) L^{S}\right]$ is decreasing in $\phi^{N}$ and increasing in $\phi^{S}$, we take the derivatives:

$\frac{d}{d \phi^{N}}\left[\left(r^{T}-r^{S}\right) K^{S}+\left(w^{T}-w^{S}\right) L^{S}\right]=\frac{d r^{T}}{d \phi^{N}} K^{S}+\frac{d w^{T}}{d \phi^{N}} L^{S}=\frac{d E^{T}}{d \phi^{N}}\left(\frac{d r^{T}}{d E^{T}} K^{S}+\frac{d w^{T}}{d E^{T}} L^{S}\right)<0$,

because, as follows from the discussion above, $\frac{d E^{T}}{d \phi^{N}}<0, \frac{d r^{T}}{d E^{T}}>0$ and $\frac{d w^{T}}{d E^{T}}>0$. Similarly,

$$
\frac{d}{d \phi^{S}}\left[\left(r^{T}-r^{S}\right) K^{S}+\left(w^{T}-w^{S}\right) L^{S}\right]=-\frac{d E^{S}}{d \phi^{S}}\left(\frac{d r^{S}}{d E^{S}} K^{S}+\frac{d w^{S}}{d E^{S}} L^{S}\right)>0 .
$$

From the expressions above it is also clear that as $\phi^{N} \rightarrow \phi^{S}$, it implies that $E^{T} \rightarrow E^{S}$, which in turn leads to $r^{T} \rightarrow r^{S}$ and $w^{T} \rightarrow w^{S}$. Therefore, the first term in the gains from trade vanishes, $\lim _{\phi^{N} \rightarrow \phi^{S}}\left[\left(r^{T}-r^{S}\right) K^{S}+\left(w^{T}-w^{S}\right) L^{S}\right]=0$. 
The second term, $\phi^{S} r^{S} x E^{S} L^{S}$ is a function of the South autarky values only. To prove that it is increasing in $\phi^{S}$ for small enough $\phi^{S}$, we take the derivative of $\phi^{S} r^{S} E^{S}$ (since $x L^{S}$ is simply a multiplicative constant that does not affect the sign):

$$
\begin{aligned}
\frac{d}{d \phi^{S}}\left(\phi^{S} r^{S} E^{S}\right) & =r E+\phi^{S}\left(\frac{d r}{d E} \frac{d E}{d \phi^{S}} E+r \frac{d E}{d \phi^{S}}\right) \\
& =r E+\phi^{S} \frac{d E}{d \phi^{S}}\left(\frac{d r}{d E} E+r\right) .
\end{aligned}
$$

Evaluated at $\phi^{S}=0$, this derivative is strictly positive: $\left.\frac{d}{d \phi^{S}}\left(\phi^{S} r^{S} E^{S}\right)\right|_{\phi^{S}=0}=r E$. Furthermore, $\frac{d}{d \phi^{S}}\left(\phi^{S} r^{S} E^{S}\right)$ is a continuous function whose derivative is finite for any $\phi^{S} \in[0,1]$. (This claim can be verified directly by using the equilibrium relationships (A.1) and (A.3) to write out explicit expressions for $\frac{d E}{d \phi^{S}}$ and $\left.\frac{d r}{d E}\right)$. These two observations imply that there exist strictly positive values of $\phi^{S}$ sufficiently close to zero, for which $\frac{d}{d \phi^{S}}\left(\phi^{S} r^{S} E^{S}\right)>0$ and therefore $\phi^{S} r^{S} x E^{S} L^{S}$ increases in $\phi^{S}$.

Proof of Proposition 3: In order to show that the expression in the proposition gives the gains from institutional comparative advantage driven trade, we must show that $\left(r^{T} K^{N}+w^{T} L^{N}\right)-\left(r^{N} K^{N}+w^{N} L^{N}\right)=0$. To do this, we show that $r^{T}=r^{N}$ and $w^{T}=w^{N}$. Following the arguments similar to the proof of Proposition 2, we observe that $r^{T}, r^{N}, w^{T}, w^{N}$ are a function of the relevant $\frac{K}{L}$-ratio only, and not of the levels of endowments. In particular, because we assumed that $\frac{K^{N}}{L^{N}}=\frac{\bar{K}}{\bar{L}}$, it will be the case that $r^{T}=r^{N}$ and $w^{T}=w^{N}$ if $E^{T}=E^{N} . E^{T}$ is given by equation (A.6), while $E^{N}$ solves:

$$
\frac{\gamma}{E^{N}}=\frac{\beta}{1-E^{N}}+\frac{\alpha\left(1+\phi^{N}\right) x}{\frac{K^{N}}{L^{N}}-x E^{N}} .
$$

Comparing these two expressions, and noting that under trade, the Northern institutions are used and therefore $\phi^{N}$ enters in (A.6), it is clear that as long as $\frac{K^{N}}{L^{N}}=\frac{\bar{K}}{\bar{L}}, E^{T}=E^{N}$.

The proof that the North's gains from trade are increasing in $\phi^{N}$ is identical to the second part of the proof of Proposition 2 .

\section{B References}

1. Acemoglu, Daron (2001) "Good Jobs versus Bad Jobs," Journal of Labor Economics, 19, 1-21.

2. Acemoglu, Daron, Pol Antràs and Elhanan Helpman (2005) "Contracts and Technology Adoption," mimeo MIT.

3. Acemoglu, Daron, and Simon Johnson (2005) "Unbundling Institutions," Journal of Political Economy, 113, 949-995.

4. Acemoglu, Daron, Simon Johnson and James Robinson (2001) "Colonial Origins of Comparative Development: An Empirical Investigation," American Economic Review, 91, 1369-1401.

5. Acemoglu, Daron, Simon Johnson and James Robinson (2002) "Reversal of Fortune: Geography and Institutions in the Making of the Modern World Income Distribution," Quarterly Journal of Economics, 117, 1231-1294. 
6. Allais, Maurice (1994) "Combats pour l'Europe, 1992-1994," Paris: Clement Juglar.

7. Anderson, James, and Douglas Marcouiller (2002) "Insecurity and the Pattern of Trade: An Empirical Investigation," The Review of Economics and Statistics, 84, 342-352.

8. Antras, Pol (2003) "Firms, Contracts, and Trade Structure," Quarterly Journal of Economics, 118, 1375-1418.

9. Antras, Pol (2005) "Incomplete Contracts and the Product Cycle," American Economic Review, 95, 1054-1073.

10. Beck, Thorsten (2003) "Financial dependence and international trade," Review of International Economics, 11, 296-316.

11. Beck, Thorsten, Asli Demirguc-Kunt, and Ross Levine (2000) "A new database on financial development and structure," World Bank Economic Review, 14, 597-605.

12. Bhagwati, Jagdish, and V.K. Ramaswami (1963) "Domestic Distortions, Tariffs and the Theory of Optimum Subsidy," The Journal of Political Economy, 71, 44-50.

13. Blanchard, Olivier and Michael Kremer (1997) "Disorganization," Quarterly Journal of Economics, 112, 1091-1126.

14. Botero, Juan, Simeon Djankov, Rafael La Porta, Florencio Lopez-de-Silanes, and Andrei Shleifer (2004) "Regulation of Labor," Quarterly Journal of Economics, 119, $1339-1382$.

15. Brander, James, and Barbara Spencer (1981) "Tariffs and the Extraction of Foreign Monopoly Rents under Potential Entry," The Canadian Journal of Economics, 14, 371-389.

16. Bulow, Jeremy and Lawrence Summers (1986) "A Theory of Dual Labor Markets with Application to Industrial Policy, Discrimination, and Keynesian Unemployment," Journal of Labor Economics, 4, 376-414.

17. Caballero, Ricardo and Mohamad Hammour (1998) "The Macroeconomics of Specificity," Journal of Political Economy 106, 724-767.

18. Claessens, Stijn and Luc Laeven (2003) "Financial Development, Property Rights, and Growth," Journal of Finance, 58, 2401-2436.

19. Coase, Ronald (1937) "The Nature of the Firm," Economica, New Series, 4, 386-405.

20. Costinot, Arnaud (2005) "Contract Enforcement, Division of Labor and the Pattern of Trade", mimeo, University of California - San Diego.

21. Cowan, Kevin and Alejandro Neut (2002) "Intermediate Goods, Institutions, and Output Per Worker," mimeo, MIT 2002.

22. Davis, Donald (1995) "Intra-Industry Trade: A Heckscher-Ohlin-Ricardo Approach," Journal of International Economics, 39, 201-226.

23. Dixit, Avinash and Victor Norman (1980) "Theory of International Trade," Cambridge University Press.

24. Feenstra, Robert, John Romalis, and Peter Schott (2002) "U.S. Imports, Exports, and Tariff Data, 1989-2001," NBER Working Paper 9387. 
25. Grossman, Gene and Elhanan Helpman (2002a) "Integration versus Outsourcing in Industry Equilibrium," Quarterly Journal of Economics, 117, 85-120.

26. Grossman, Gene and Elhanan Helpman (2002b) "Outsourcing versus FDI in Industry Equilibrium," Journal of the European Economic Association, 1, 317-327.

27. Grossman, Gene and Elhanan Helpman (2005) "Outsourcing in a Global Economy," Review of Economic Studies, 72, 135-159.

28. Grossman, Sanford, and Oliver Hart (1986) "The Costs and Benefits of Ownership: A Theory of Vertical and Lateral Integration," Journal of Political Economy, 94, 691719 .

29. Haberler, Gottfried (1950) "Some Problems in the Pure Theory of International Trade," The Economic Journal, 60, 223-240.

30. Hagen, Everett (1958) "An Economic Justification of Protectionism," The Quarterly Journal of Economics, 72, 496-514.

31. Hall, Robert, and Chad Jones (1999) "Why Do Some Countries Produce So Much More Output per Worker then Others," Quarterly Journal of Economics, 114, 83116.

32. Hart, Oliver, and John Moore (1990) "Property Rights and the Nature of the Firm," Journal of Political Economy, 98, 1119-1158.

33. Helpman, Elhanan, and Paul Krugman (1985) "Market Structure and Foreign Trade," MIT Press, Cambridge, MA.

34. Heston, Alan, Robert Summers, and Bettina Aten (2002) "Penn World Table Version 6.1," Center for International Comparisons at the University of Pennsylvania (CICUP).

35. Hillman, Arye L. (1989) "The Political Economy of Protection," Harwood Academic Publishers, Chur, Switzerland.

36. Johnson, Simon, John McMillan, and Christopher Woodruff (2002a) "Courts and Relational Contracts," Journal of Law, Economics and Organization, 18, 221-277.

37. Johnson, Simon, John McMillan, and Christopher Woodruff (2002b) "Property Rights and Finance," American Economic Review, 92, 1335-1356.

38. Ju, Jiandong, and Shang-Jin Wei (2005) "Endowment versus Finance: A Wooden Barrel Theory of International Trade," IMF Working Paper No. 05/123.

39. Kaufmann, Daniel, Aart Kraay, and Massimo Mastruzzi (2005) "Governance Matters IV: Governance Indicators for 1996-2004" mimeo, The World Bank.

40. Klein, Benjamin, Robert Crawford, and Armen Alchian (1978) "Vertical Integration, Appropriable Rents, and the Competitive Contracting Process," Journal of Law and Economics, 21, 297-326.

41. La Porta, Rafael, Florencio Lopez-de-Silanes, Andrei Shleifer, and Robert Vishny (1997) "Legal Determinants of External Finance," Journal of Finance, 52, 1131-1150.

42. La Porta, Rafael, Florencio Lopez-de-Silanes, Andrei Shleifer, and Robert Vishny (1998) "Law and Finance," Journal of Political Economy, 106, 1113-1155.

43. Lawson, Ann (1997) "Benchmark Input-Output Accounts for the U.S. Economy, 1992," Survey of Current Business, Nov. 1997. 
44. Macchiavello, Rocco (2005) "Contractual Imperfections, Credit Markets and Vertical Integration: Theory and Cross-Country Evidence," mimeo, LSE.

45. Matsuyama, Kiminori (2005) "Credit Market Imperfections and Patterns of International Trade and Capital Flows," Journal of the European Economic Association, 3, 714-723.

46. McMillan, John, and Christopher Woodruff (1999) "Interfirm Relationships and Informal Credit in Vietnam," Quarterly Journal of Economics, 114, 1285-1320.

47. Nunn, Nathan (2005) "Relationship-Specificity, Incomplete Contracts and the Pattern of Trade," mimeo, University of British Columbia.

48. Rajan, Raghuram, and Luigi Zingales (1998) "Financial dependence and growth," American Economic Review, 88, 559-586.

49. Ranjan, Priya, and Jae Young Lee (2003) "Contract enforcement and the volume of international trade in different types of goods," mimeo, UC Irvine.

50. Romalis, John (2004) "Factor Proportions and the Structure of Commodity Trade," American Economic Review, 94, 67-97.

51. Schuler, Philip (2003) "Institutions and the Changing Composition of International Trade in the Post-Socialist Transition," PhD Dissertation, University of Maryland, 2002.

52. Vogel, Jonathan (2006) "Institutions and Moral Hazard in Open Economies," mimeo, Princeton.

53. Williamson, Oliver (1985) "The Economic Institutions of Capitalism: Firms, Markets, Relational Contracting," The Free Press, 1985.

54. World Bank (2006) "Doing Business in 2006: Creating Jobs," Wachington, DC: The World Bank and the International Finance Corporation. 
Figure 1: The World Economy and the Factor Price Equalization Set

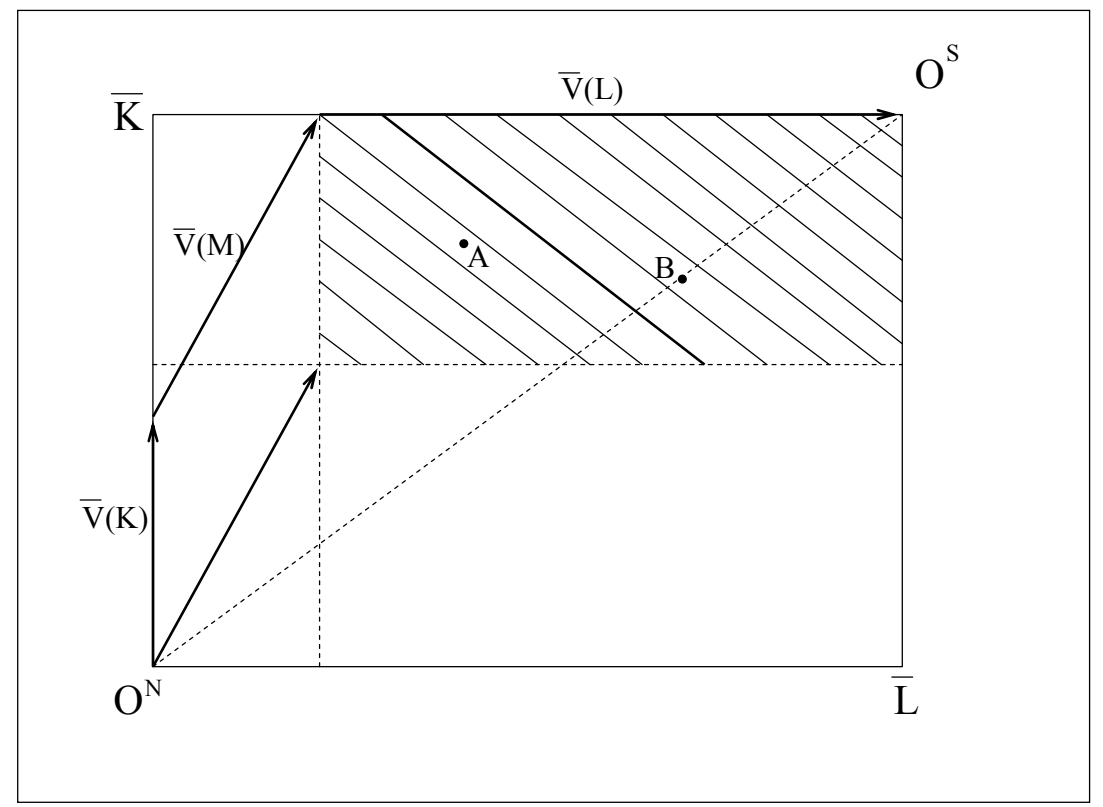

Figure 2: The Pattern of Production

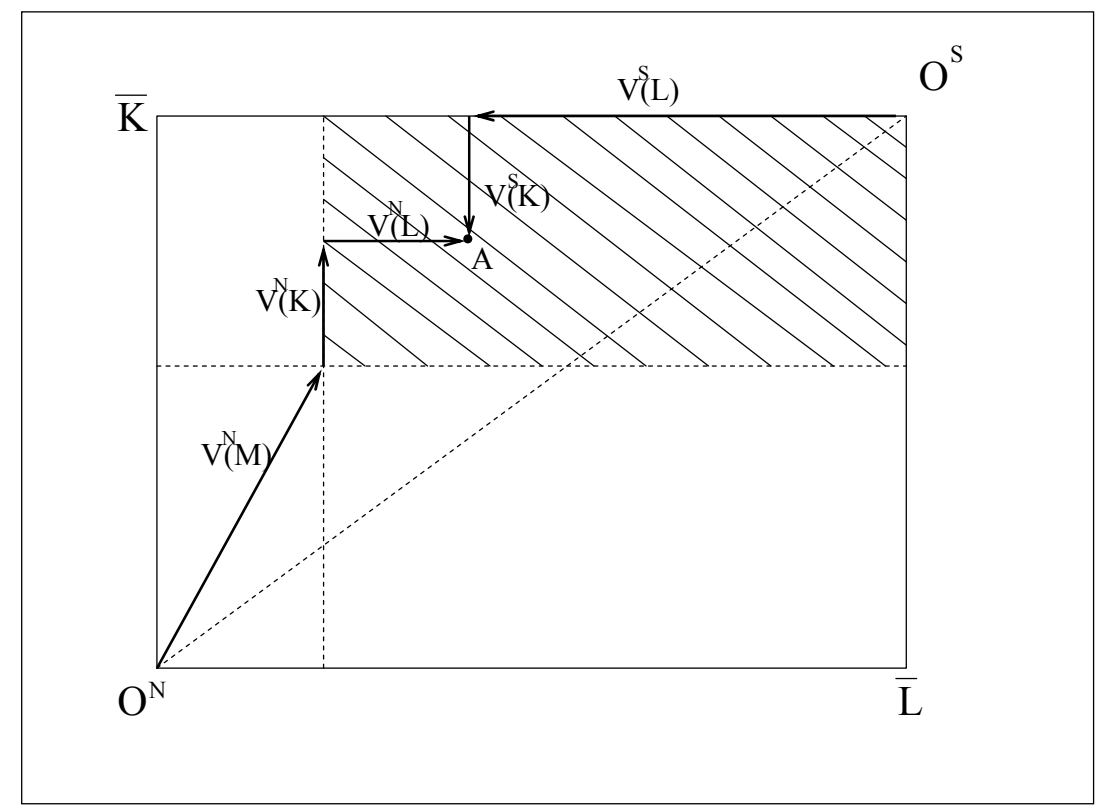


Figure 3: The South's Gains from Trade as a Function of Institutions

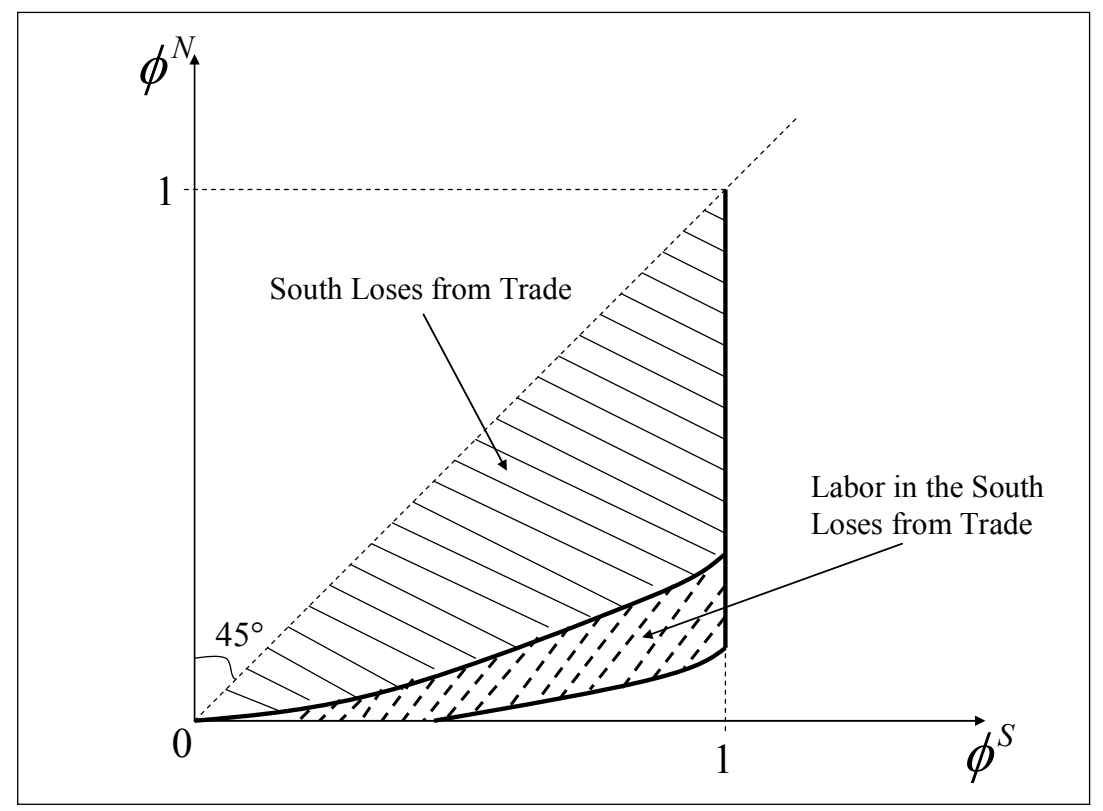

Figure 4: Production Pattern Outside of FPE

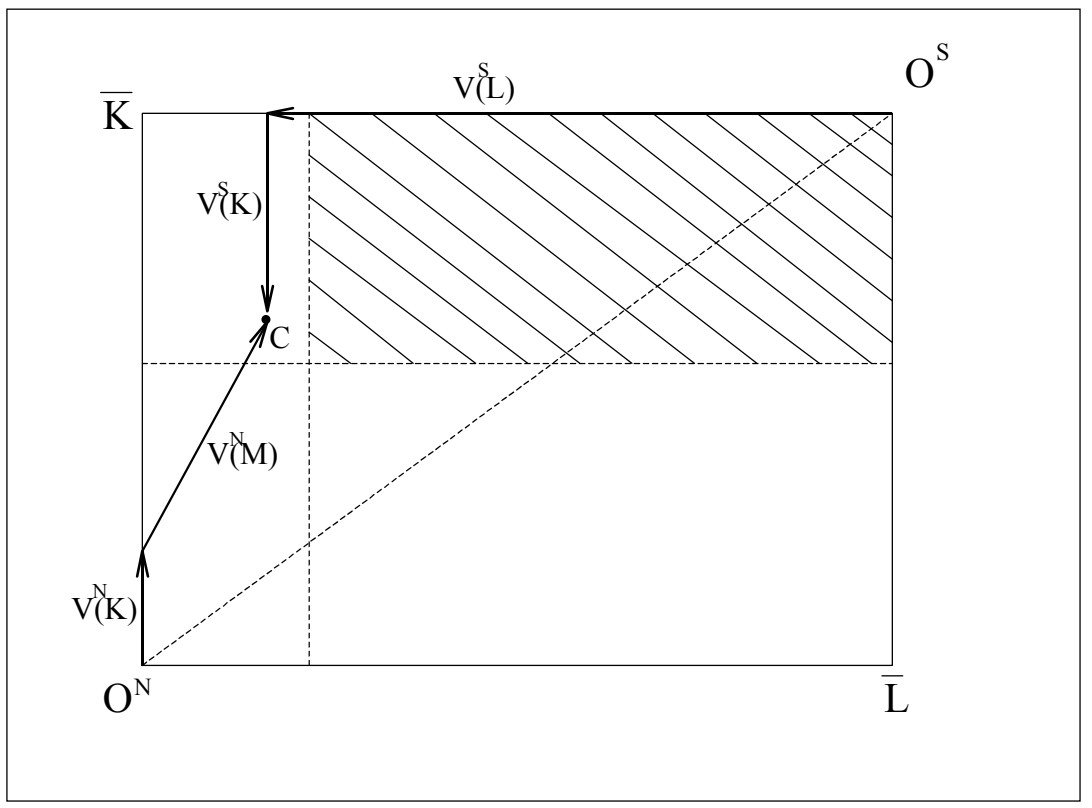




\section{Table 1: Baseline Specification and Alternative Measures of Institutional Intensity}

\begin{tabular}{|c|c|c|c|c|c|}
\hline & $(1)$ & $(2)$ & (3) & $(4)$ & $(5)$ \\
\hline (herfindahl index)*inst & $\begin{array}{c}2.33 \\
(0.60)^{* * * *}\end{array}$ & & & & \\
\hline (share of 20 largest interm.)*inst & & $\begin{array}{c}4.05 \\
(0.53)^{* * *}\end{array}$ & & & \\
\hline (gini coefficient)*inst & & & $\begin{array}{c}20.70 \\
(2.92)^{* * *}\end{array}$ & & \\
\hline (number of intermediates/1000)*inst & & & & $\begin{array}{c}3.12 \\
(1.54)^{* *}\end{array}$ & \\
\hline (investment/output)*inst & & & & & $\begin{array}{c}3.98 \\
(1.47)^{* * *}\end{array}$ \\
\hline (skill intensity)*(skill endow) & $\begin{array}{c}11.35 \\
(2.19)^{* * *}\end{array}$ & $\begin{array}{c}7.58 \\
(2.22)^{* * *}\end{array}$ & $\begin{array}{c}7.66 \\
(2.24)^{* * *}\end{array}$ & $\begin{array}{c}13.60 \\
(2.12)^{* * *}\end{array}$ & $\begin{array}{c}14.11 \\
(2.09)^{* * *}\end{array}$ \\
\hline (capital intensity)*(cap. endow) & $\begin{array}{c}0.50 \\
(0.28)^{*}\end{array}$ & $\begin{array}{c}0.55 \\
(0.28)^{*}\end{array}$ & $\begin{array}{c}0.54 \\
(0.28)^{*}\end{array}$ & $\begin{array}{c}0.41 \\
-(0.29) \\
\end{array}$ & $\begin{array}{c}0.38 \\
-(0.28) \\
\end{array}$ \\
\hline Country Dummies & yes & yes & yes & yes & yes \\
\hline Industry Dummies & yes & yes & yes & yes & yes \\
\hline Observations & 31568 & 31568 & 31568 & 31568 & 31568 \\
\hline Industries & 389 & 389 & 389 & 389 & 389 \\
\hline Countries & 116 & 116 & 116 & 116 & 116 \\
\hline
\end{tabular}

Notes: Robust standard errors in parentheses; $*$ significant at $10 \%$; ** significant at $5 \%$; *** significant at $1 \%$; Herfindahl index of intermediate good use measures institutional intensity; inst is an index of institutional quality (rule of law) from Kaufmann, Kraay and Mastruzzi (2005); capital intensity=1-(total compensation)/(value added); skill intensity $=\left[(\text { nonproduction workers)/(total employment) }]^{*}(1\right.$-capital intensity); skill endow. and cap. endow are natural logs of human and physical capital per worker, respectively, obtained from Hall and Jones (1999). Gini coefficient of intermediate good use, share of 20 largest intermediates, number of intermediates/1000, and investment/output ratio are measures of institutional intensity. Variable definitions and sources described in detail in the text. 
Table 2: Alternative Specifications

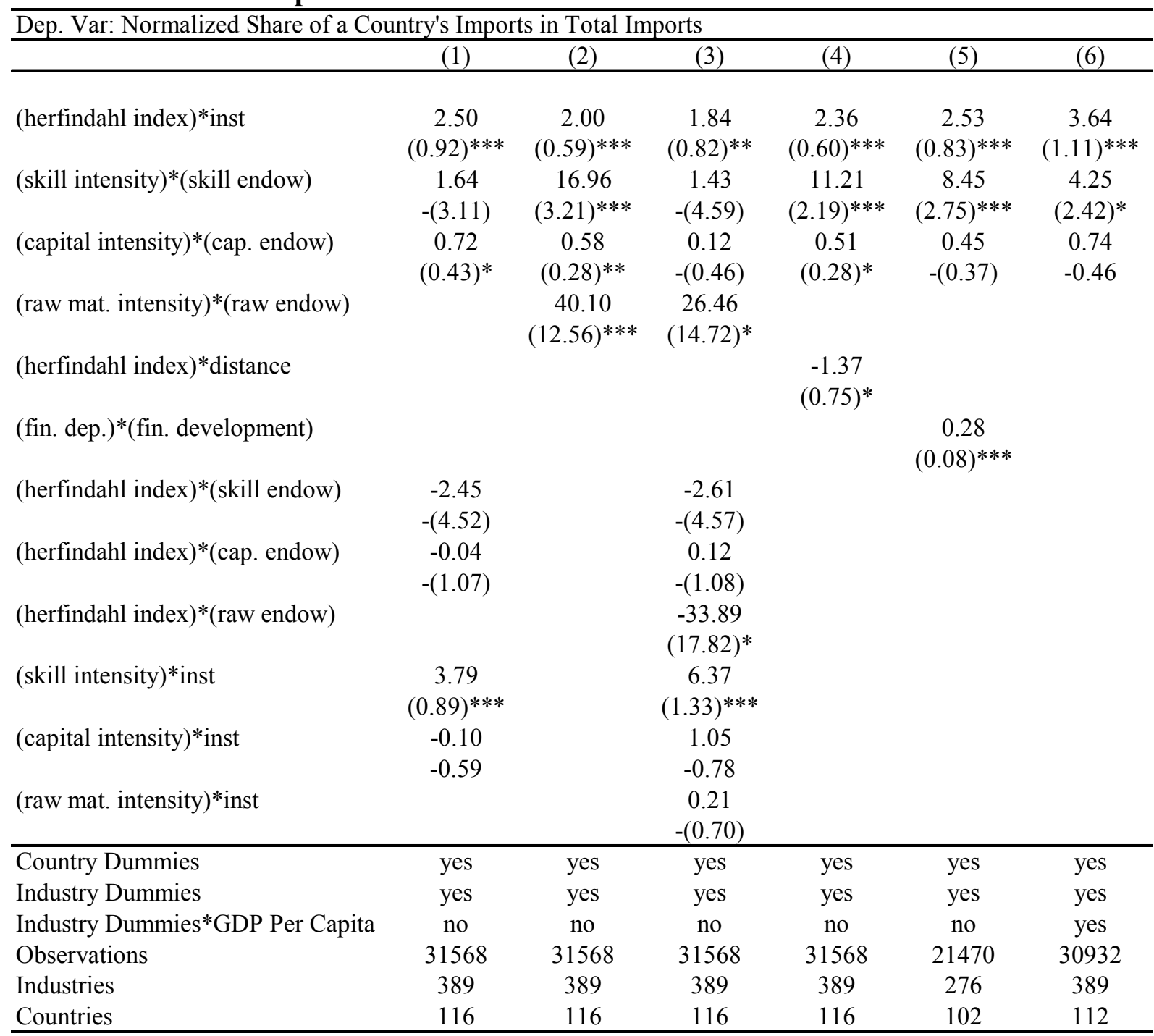

Notes: Robust standard errors in parentheses; * significant at $10 \%$; ** significant at $5 \%$; *** significant at $1 \%$; Herfindahl index of intermediate good use measures institutional intensity; inst is an index of institutional quality (rule of law) from Kaufmann, Kraay and Mastruzzi (2005). In a 3-factor model, capital intensity=1-(total compensation) $/\left(\right.$ value added); skill intensity $=[\text { (nonproduction workers)/(total employment) }]^{*}(1$-capital intensity). In a 4-factor model, raw material intensity=(value of raw material inputs)/(value of raw material inputs + value added); capital intensity $=[1-($ total compensation $) /($ value added $)] *(1-$ raw material intensity $)$ skill intensity $=[$ (nonproduction workers)/(total employment) $]^{*}$ (1-capital intensity)*(1-raw material intensity). skill endow. and cap. endow are natural logs of human and physical capital per worker, respectively, obtained from Hall and Jones (1999). Distance is bilateral log distance between the US and each trading partner, taken from CEPII. Financial dependence is a measure of dependence on external finance calculated from firm-level Compustat data following the methodology of Rajan and Zingales (1998). Financial development is the ratio of private credit to GDP obtained from Beck et al. (2000). The last column interacts sector fixed effects with the log of PPP-adjusted GDP per capita from the Penn World Tables. Variable definitions and sources described in detail in the text. 
Table 3: Alternative Samples

\begin{tabular}{lcccc}
\hline \multicolumn{5}{c}{ Dep. Var: Normalized Share of a Country's Imports in Total Imports } \\
\hline & $(1)$ & $(2)$ & $(3)$ & $(4)$ \\
\hline & & & & \\
(herfindahl index)*inst & 3.57 & 1.56 & 2.20 & 2.28 \\
& $(1.20)^{* * *}$ & $(0.55)^{* * *}$ & $(0.65)^{* * *}$ & $(0.61)^{* * *}$ \\
(skill intensity)*(skill endow) & 2.07 & 18.78 & 12.97 & 11.52 \\
& $-(3.16)$ & $(2.64)^{* * *}$ & $(2.17)^{* * *}$ & $(2.24)^{* * *}$ \\
(capital intensity)*(cap. endow) & 0.42 & 1.51 & 0.55 & 0.50 \\
& $-(0.41)$ & $(0.26)^{* * *}$ & $(0.29)^{*}$ & $(0.29)^{*}$ \\
\hline Country Dummies & yes & yes & yes & yes \\
Industry Dummies & yes & yes & yes & yes \\
Observations & 22912 & 26842 & 28146 & 30673 \\
Specification & South only & No Africa & No SE Asia & No outliers \\
Industries & 389 & 389 & 389 & 379 \\
Countries & 93 & 79 & 106 & 116 \\
\hline
\end{tabular}

Notes: Robust standard errors in parentheses; * significant at $10 \%$;* significant at $5 \%$; *** significant at $1 \%$; Herfindahl index of intermediate good use measures institutional intensity; inst is an index of institutional quality (rule of law) from Kaufmann, Kraay and Mastruzzi (2005); capital intensity=1-(total compensation)/(value added); skill intensity $=\left[(\text { nonproduction workers)/(total employment) }]^{*}(1\right.$-capital intensity); skill endow. and cap. endow are natural logs of human and physical capital per worker, respectively, obtained from Hall and Jones (1999). Variable definitions and sources described in detail in the text. 


\section{Appendix Tables}

\section{Appendix Table A1: Sectors with Highest and Lowest Institutional Intensity}

\begin{tabular}{rll}
\hline \multicolumn{3}{c}{ Least Institutionally Intensive Industries } \\
\hline & & \\
2 & 2011 & Meat packing plants \\
3 & 2075 & Soybean oil mills \\
4 & 2015 & Poultry slaughtering and processing \\
5 & 2429 & Special product sawmills, n.e.c. \\
6 & 2911 & Creamery butter \\
7 & 2026 & Fluid milk \\
8 & 2296 & Tire cord and fabrics \\
9 & 2083 & Malt \\
10 & 2652 & Setup paperboard boxes
\end{tabular}

Most Institutionally Intensive Industries

\begin{tabular}{lcccc}
\multicolumn{5}{l}{ Appendix Table A2: Industry-Level Summary Statistics } \\
\hline & Mean & Std. Dev. & Min & Max \\
\hline & & & & \\
herfindahl index of intermediate use & -0.133 & 0.093 & -0.780 & -0.035 \\
capital intensity & 0.623 & 0.114 & 0.181 & 0.951 \\
skill intensity & 0.110 & 0.057 & 0.014 & 0.484 \\
& & & & \\
\hline
\end{tabular}

Appendix Table A3: Country-Level Summary Statistics

\begin{tabular}{lcccc}
\hline & Mean & Std. Dev. & Min & Max \\
\hline & & & & \\
inst & 0.094 & 1.052 & -1.885 & 2.242 \\
log of human capital per worker & 0.580 & 0.292 & 0.072 & 1.215 \\
log of physical capital per worker & 9.203 & 1.587 & 5.763 & 11.589 \\
& & & & \\
\hline
\end{tabular}

\section{Appendix Table A4: Correlation Coefficients between Alternative Institutional Intensity} Indices

\begin{tabular}{lcccc}
\hline & share20 & gini & no. of int. & inv/out \\
\hline herfindahl index of intermediate use & 0.67 & 0.7419 & 0.2314 & 0.1457 \\
\hline
\end{tabular}


Appendix Table A5: Country List

\begin{tabular}{|c|c|c|c|}
\hline North & South & & \\
\hline Australia & Algeria & Guatemala & Paraguay \\
\hline Austria & Angola & Guinea & Peru \\
\hline Belgium & Argentina & Guinea-Bissau & Philippines \\
\hline Canada & Bangladesh & Guyana & Poland \\
\hline Denmark & Barbados & Haiti & Portugal \\
\hline Finland & Benin & Honduras & Romania \\
\hline France & Bolivia & Hungary & Russian Federation \\
\hline Germany & Brazil & India & Rwanda \\
\hline Hong Kong, China & Burkina Faso & Indonesia & Saudi Arabia \\
\hline Iceland & Burundi & Jamaica & Senegal \\
\hline Ireland & Cameroon & Jordan & Seychelles \\
\hline Israel & Central African Republic & Kenya & Sierra Leone \\
\hline Italy & Chad & Korea, Rep. & Somalia \\
\hline Japan & Chile & Madagascar & South Africa \\
\hline Netherlands & China & Malawi & Sri Lanka \\
\hline New Zealand & Colombia & Malaysia & Sudan \\
\hline Norway & Comoros & Mali & Suriname \\
\hline Singapore & Congo, Dem. Rep. & Malta & Syrian Arab Republic \\
\hline Spain & Congo, Rep. & Mauritania & Tanzania \\
\hline Sweden & Costa Rica & Mauritius & Thailand \\
\hline Switzerland & Cote d'Ivoire & Mexico & Togo \\
\hline Taiwan, POC & Cyprus & Morocco & Trinidad and Tobago \\
\hline \multirow[t]{9}{*}{ United Kingdom } & Dominican Republic & Mozambique & Tunisia \\
\hline & Ecuador & Myanmar & Turkey \\
\hline & Egypt, Arab Rep. & Nicaragua & Uganda \\
\hline & El Salvador & Niger & Uruguay \\
\hline & Fiji & Nigeria & Venezuela, RB \\
\hline & Gabon & Oman & Yemen, Rep. \\
\hline & Gambia, The & Pakistan & Yugoslavia, Fed. Rep. \\
\hline & Ghana & Panama & Zambia \\
\hline & Greece & Papua New Guinea & Zimbabwe \\
\hline
\end{tabular}

